\title{
Assimilation of All-Sky SEVIRI Infrared Brightness Temperatures in a Regional-Scale Ensemble Data Assimilation System
}

\author{
JASON A. OTKIN \\ Department of Mathematics and Statistics, University of Reading, Reading, United Kingdom, and \\ Cooperative Institute for Meteorological Satellite Studies, Space Science and Engineering Center, \\ University of Wisconsin-Madison, Madison, Wisconsin \\ ROLAND POTTHAST \\ Deutscher Wetterdienst, Offenbach, Germany, and Department of Mathematics and Statistics, \\ University of Reading, Reading, United Kingdom
}

(Manuscript received 1 May 2019, in final form 12 August 2019)

\begin{abstract}
Ensemble data assimilation experiments were performed to assess the ability of satellite all-sky infrared brightness temperatures and different bias correction (BC) predictors to improve the accuracy of short-range forecasts used as the model background during each assimilation cycle. Satellite observations sensitive to clouds and water vapor in the upper troposphere were assimilated at hourly intervals during a 3-day period. Linear and nonlinear conditional biases were removed from the infrared observations using a Taylor series polynomial expansion of the observation-minus-background departures and $\mathrm{BC}$ predictors sensitive to clouds and water vapor or to variations in the satellite zenith angle. Assimilating the all-sky infrared brightness temperatures without $\mathrm{BC}$ degraded the forecast accuracy based on comparisons to radiosonde observations. Removal of the linear and nonlinear conditional biases from the satellite observations substantially improved the results, with predictors sensitive to the location of the cloud top having the largest impact, especially when higher-order nonlinear BC terms were used. Overall, experiments employing the observed cloud-top height or observed brightness temperature as the bias predictor had the smallest water vapor, cloud, and wind speed errors, while also having less degradation to temperatures than occurred when using other predictors. The forecast errors were smaller during these experiments because the cloud-height-sensitive BC predictors were able to more effectively remove the large conditional biases for lower brightness temperatures associated with a deficiency in upper-level clouds in the model background.
\end{abstract}

\section{Introduction}

Indirect observations of the atmosphere, ocean, and land surface conditions obtained using sophisticated satellite remote sensing instruments are an indispensable component of the global observing system. For numerical weather prediction (NWP) applications, satellite radiances from visible, infrared, and microwave bands provide important information about atmospheric variables, such as temperature, winds, water vapor, and clouds, as well as lower boundary variables such as soil moisture, vegetation biomass, and sea surface temperatures. Satellite observations can also be used to detect the presence of aerosols and trace gases that are important for health and air quality models.

Corresponding author: Jason A. Otkin, jasono@ssec.wisc.edu
Recent enhancements to the global satellite observing system through deployment of more accurate sensors on board geostationary and polar-orbiting satellite platforms has made it possible to routinely monitor environmental conditions with high spatial and temporal resolution across the entire globe (Klaes et al. 2007; Strow et al. 2013; Bessho et al. 2016; Schmit et al. 2017).

As satellite remote sensing capabilities have expanded and improved during the past several decades, substantial progress has also been made in our ability to extract more information from these important observations through development of advanced data assimilation (DA) methods and more accurate NWP models. Despite using only a small percentage of all available observations, satellite brightness temperatures and derived products such as atmospheric motion vectors still constitute more than $90 \%$ of the observations 
that are actively assimilated in most operational global NWP models (Bauer et al. 2010). Satellite observations are especially important in data-sparse regions or for model state variables such as clouds and water vapor for which conventional in situ observations with high spatial and temporal resolution are not available.

Until the past decade, however, almost all efforts within the operational and research DA communities were directed toward optimizing the use of clear-sky brightness temperatures. This point of emphasis was not made because cloud-impacted observations were deemed unimportant, but rather, was due to the difficulty of using them in existing DA systems (Errico et al. 2007). Indeed, until the recent development of all-sky DA methods, the need to exclude observations impacted by clouds and precipitation meant that only a small percentage of available satellite observations were actively assimilated at global NWP centers (Yang et al. 2016; Mallick et al. 2017). This limitation is even more severe for regional-scale NWP models where the entire domain may be covered by clouds (Lin et al. 2017). Though more effective assimilation of clear-sky satellite brightness temperatures has contributed to a steady increase in forecast skill, neglecting observations impacted by clouds is problematic because they tend to be located in dynamically active regions where the generation of more accurate initialization datasets through better use of these observations could help constrain potentially rapid error growth in NWP models (McNally 2002).

Observations sensitive to clouds and precipitation are challenging to use for a variety of reasons, as discussed by Errico et al. (2007). For example, though observation-minus-background (OMB) departure statistics are generally close to Gaussian for clear-sky observations, they can have substantial non-Gaussian error characteristics in the presence of clouds and precipitation (Bocquet et al. 2010; Okamoto et al. 2014; Okamoto 2017; Harnisch et al. 2016; Otkin et al. 2018). Short-range model forecasts used as the first guess often exhibit large errors in the placement and characteristics of clouds and precipitation. Limited predictability of small-scale features and the difficulty of accurately modeling moist processes means that it is common for the model first guess to have much larger errors for clouds and precipitation than it does for dynamical variables such as temperature and geopotential height (Fabry and Sun 2010). Though representativeness errors can usually be ignored when assimilating clear-sky observations primarily sensitive to temperature, they become important for cloud-affected observations because they can lead to very large OMB departures that hinder their assimilation (Geer and Bauer 2011; Geer et al.
2012; Okamoto 2013). It is also more difficult to quantify the observation and model background errors because it can be challenging to separate signals associated with the individual atmospheric and land surface variables that contribute to the sensitivity of a given satellite observation (Bauer et al. 2011). Another prominent problem is the difficulty of modeling complex cloud properties in the radiative transfer models used to compute the model-equivalent brightness temperatures. Nonlinear error statistics due to deficiencies in the radiative transfer and NWP models could lead to erroneous analysis increments in the model state variables that in turn could impact balance and stability during the first few hours of the forecast (Errico et al. 2007). Last, it is also important to account for correlated observation errors because they can become very large in the presence of clouds and precipitation (Bormann et al. 2011, 2016; Campbell et al. 2017).

Despite these and other issues that make it more challenging to assimilate cloud-sensitive observations, substantial progress has still been made during the past decade (Geer et al. 2017, 2018). Successful efforts to assimilate all-sky satellite observations have occurred in tandem with improvements in the representation of water vapor and cloud features in NWP models and advances in the ability of radiative transfer models to accurately model radiative fluxes in clouds. These efforts have also been aided through the widespread adoption of four-dimensional variational data assimilation (4DVAR) and ensemble DA methods that can more easily extract information about dynamical variables from cloud- and moisture-sensitive observations (Geer et al. 2014; Lien et al. 2016; Zhu et al. 2016). For example, Peubey and McNally (2009) demonstrated that four-dimensional variational methods could extract useful information about the wind field from moisturesensitive satellite observations through the "traceradvection" mechanism. Likewise, ensemble DA systems can infer the temperature, water vapor, and wind fields through ensemble covariances that link the model state variables to the simulated observations (Zhang et al. 2011; Houtekamer and Zhang 2016). Compared to DA methods that only assimilate clear-sky satellite observations, an important benefit of an all-sky DA approach is that it provides a unified treatment of cloud-free and cloud-impacted observations that negates the need to perform potentially unreliable and expensive cloud detection procedures (Bauer et al. 2010). An all-sky DA approach also promotes a more balanced use of satellite observations in clear and cloudy areas that helps overcome the tendency for operational DA systems to assimilate substantially more observations in regions that are not affected by clouds or precipitation (Geer et al. 2017). 
Early efforts to assimilate all-sky satellite observations focused on microwave sounding channels that are sensitive to water vapor and nonprecipitating cloud particles (Bauer et al. 2010). These channels were initially chosen because they have more Gaussian error characteristics than cloud-sensitive infrared and visible channels, thereby making them a logical starting point to explore the assimilation of all-sky observations. Whereas it was once thought that it may prove too difficult to assimilate water vapor and cloud-sensitive satellite observations (e.g., Bengtsson and Hodges 2005), their impact has increased greatly in recent years (Geer et al. 2018). The direct assimilation of all-sky microwave observations was first accomplished in an operational DA system in 2009 at the European Centre for Medium-Range Weather Forecasts (ECMWF) (Bauer et al. 2010). Since then, the impact of these observations has risen to nearly $20 \%$ (Geer et al. 2017), as measured using the forecast sensitivity observation impact metric (Langland and Baker 2004). This rapid increase in their impact means that all-sky microwave observations have become one of the most important sources of data in the ECMWF model, with an impact comparable to clear-sky satellite radiances and conventional observations. More recently, the National Centers for Environmental Prediction has also started to assimilate all-sky microwave observations in their operational global forecasting system (Zhu et al. 2016). Numerous studies have documented the benefits of assimilating all-sky microwave observations in global and regional modeling systems (e.g., Aonashi and Eito 2011; Geer et al. 2014; Yang et al. 2016; Kazumori et al. 2016; Baordo and Geer 2016; Zhang and Guan 2017; Lawrence et al. 2018; Wu et al. 2019).

In contrast to the extensive resources that have been directed by the operational DA community toward the assimilation of all-sky microwave observations, much less attention has been given to increasing the use of cloud-sensitive infrared brightness temperatures. Indeed, until the past few years, most studies that explored the assimilation of all-sky infrared observations have done so using research models or within the context of observing system simulation experiments (OSSEs). Early studies by Vukicevic et al. $(2004,2006)$ assimilated cloudy-sky infrared brightness temperatures from the 10.7- and $12.0-\mu \mathrm{m}$ bands on the Geostationary Operational Environmental Satellite (GOES) Imager using a 4DVAR assimilation system. Observations from these atmospheric window bands were shown to improve the depiction of upper-level ice clouds; however, they had less impact on liquid clouds occurring lower in the troposphere. Subsequent studies by Stengel et al. (2009, 2013) found that assimilation of cloud-impacted infrared observations from the 6.2- and 7.3- $\mu \mathrm{m}$ water vapor channels on the Spinning Enhanced Visible and Infrared Imager (SEVIRI) sensor led to more accurate analyses and forecasts in a high-resolution regional-scale model. Other investigators proposed several methods that could be used to assimilate information from cloudimpacted observations from hyperspectral sounders on board polar-orbiting satellite platforms (Heilliette and Garand 2007; Pavelin et al. 2008; McNally 2009; Pangaud et al. 2009; Guidard et al. 2011; Lupu and McNally 2012). All of these methods were designed to estimate the cloud-top pressure or effective cloud amount, with these parameters then fed to the DA system. This process enabled the assimilation of some cloud information from these observations.

The direct assimilation of cloud and water vapor sensitive infrared brightness temperatures has also been investigated using regional-scale OSSEs. Most of these studies employed ensemble DA systems and were used to examine the potential impact of assimilating observations from the Advanced Baseline Imager (ABI) on board the GOES-R satellite (currently GOES-16 and GOES-17). In studies assimilating both clearand cloudy-sky brightness temperatures from the ABI $8.5-\mu \mathrm{m}$ band, Otkin $(2010,2012 \mathrm{a})$ showed that their assimilation improved the cloud field and that it was necessary to use a short horizontal localization radius to account for small-scale cloud features in the infrared observations. A subsequent study by Otkin (2012b) revealed that assimilation of all-sky observations from the three water vapor sensitive bands on the ABI sensor had a large positive impact on 6-h precipitation forecasts during a high-impact winter storm. Jones et al. (2013a, 2014) examined the impact of simultaneously assimilating all-sky ABI brightness temperatures and Doppler radar reflectivity observations for an extratropical cyclone, where it was found that the most accurate analyses and forecasts were obtained when both observation types were assimilated because they are sensitive to different portions of the cloud field. The radar observations had a large positive impact on the cloud and wind fields in the lower troposphere, whereas the satellite observations provided additional improvements in the cloud and moisture fields in the upper troposphere. Other OSSE studies have shown similar positive results for various weather features, such as mesoscale convective systems and tropical cyclones (Zupanski et al. 2011; Cintineo et al. 2016; Zhang et al. 2016; Minamide and Zhang 2017, 2018; Pan et al. 2018).

Results from the various OSSE studies have been used to inform ongoing efforts by various groups to assimilate real all-sky infrared brightness temperatures and satellite-derived products. Most of these studies 
have focused on optimizing methods to assimilate data from geostationary satellite sensors in regional-scale ensemble DA systems. Geostationary satellite observations are very useful for these models because they are the only source of cloud and water vapor information with high spatial resolution. Moreover, unlike polar-orbiting satellites, geostationary sensors are also able to provide frequent observation updates that cover most, if not all, of the model domain. Some recent studies have shown positive results when assimilating satellite-derived products such as cloud water path or layer precipitable water (Jones et al. 2013b, 2015, 2016, 2018; Schomburg et al. 2015; Jones and Stensrud 2015; Kerr et al. 2015; Wang et al. 2018), whereas other studies have explored the direct assimilation of all-sky infrared brightness temperatures. Regardless, there is great potential in assimilating all-sky geostationary satellite observations in regional-scale models because clouds are the first observable aspect of convective systems (Gustafsson et al. 2018; Kurzrock et al. 2018).

Okamoto (2013) showed a slightly positive impact on temperature and wind analyses and 6-h forecasts when a subset of infrared brightness temperatures depicting spatially homogeneous clouds in the middle and upper troposphere were assimilated. Subsequent studies by Okamoto et al. (2014) and Harnisch et al. (2016) developed cloud-dependent all-sky observation error models where the error is allowed to vary as a function of a diagnosed cloud impact parameter. Similar in construct to the "symmetric" observation error model developed by Geer and Bauer (2011) for all-sky microwave observations, both models assign the largest errors to the most strongly cloud-impacted observations given greater uncertainties in both the NWP and radiative transfer models in cloudy scenes. Minamide and Zhang (2017) have proposed an alternative method, known as adaptive observation error inflation, that scales the observation errors as a function of the first guess departure, with the largest errors given to observations with the largest departures. Application of these dynamical observation error models to all-sky infrared brightness temperatures generally leads to more Gaussian departure statistics.

Other studies have shown that assimilation of all-sky infrared observations from geostationary satellite sensors can improve forecasts for tropical cyclones, floods, and severe thunderstorms (Zhang et al. 2016, 2018; Honda et al. 2018a,b; Minamide and Zhang 2018). In particular, these case studies revealed that assimilation of all-sky observations improved the prediction of the midlevel mesocyclone during a tornadic thunderstorm and the structure of the inner core and outer rainband regions for several tropical cyclones. More accurate precipitation forecasts were also shown to lead to more skillful flood forecasts from a river discharge model (Honda et al. 2018b). Though the direct assimilation of all-sky infrared brightness temperatures is currently not included in any operational DA system, Geer et al. (2019) present promising early results from a semioperational implementation of the ECMWF model. Their study assimilated all-sky observations from seven water vapor sensitive bands on the Infrared Atmospheric Sounding Interferometer sensor on board the polar-orbiting $\mathrm{Met} O p$ - $A$ and $\mathrm{Met} O \mathrm{P}-\mathrm{B}$ satellites. It was shown that the newly developed all-sky DA approach gave results that were as good or better than the existing clear-sky-only approach, with the largest benefits found in the tropics where short-range forecasts were improved throughout the troposphere and stratosphere.

In this study, we advance efforts to assimilate all-sky infrared brightness temperatures from the cloud and water vapor sensitive $6.2-\mu \mathrm{m}$ band on the SEVIRI sensor using a preoperational version of the Kilometerscale Ensemble Data Assimilation (KENDA) system run at the German Deutscher Wetterdienst (DWD). Experiments are run in which the nonlinear bias correction (NBC) method developed by Otkin et al. (2018) is used to remove systematic biases from the all-sky observations prior to their assimilation. Given the proven utility of clear-sky satellite BC methods (Eyre 2016), it is necessary to develop cloud-dependent BC methods for all-sky infrared brightness temperatures to make full use of these observations within modern DA systems. Cloud-dependent biases can occur for a variety of reasons. For example, deficiencies in the forward radiative transfer model used to compute the modelequivalent brightness temperatures, or the inability of the parameterization schemes in the NWP model to accurately represent the spatial extent, thickness, and optical properties of clouds, can introduce systematic errors that vary as a nonlinear function of some cloud property, such as cloud-top height (Dee 2005; Dee and Uppala 2009; Mahfouf 2010; Otkin and Greenwald 2008; Cintineo et al. 2014; Eikenberg et al. 2015). Though the accuracy of radiative transfer models has improved greatly in recent years, there are still large uncertainties regarding the specification of cloud properties, especially for ice clouds (Yang et al. 2013; Baum et al. 2014; Yi et al. 2016).

Most BC methods use a set of predictors describing aspects of the atmospheric state or characteristics of the satellite data to remove biases from the OMB departures (Eyre 2016). So-called "static" BC methods use a set of departures accumulated over long periods of time outside of the DA system to estimate and remove biases from the observations (Eyre 1992; Harris and 
Kelly 2001; Hilton et al. 2009). In contrast to the nontime-varying $\mathrm{BC}$ coefficients derived using static methods, variational $B C$ (VarBC) methods update the BC coefficients during each DA cycle using an augmented control vector (Derber et al. 1991; Parrish and Derber 1992; Derber and Wu 1998; Dee 2005; Auligne et al. 2007; Dee and Uppala 2009; Zhu et al. 2014, 2016). Recently, Zhu et al. (2016) expanded an existing operational VarBC method so that it could be used to remove biases from all-sky microwave observations. To reduce errors associated with mismatched cloud fields, the BC coefficients with this method were computed using only situations where both the observed and modelequivalent brightness temperatures were diagnosed as clear or cloudy. Though most studies have focused on variational, hybrid, and ensemble-variational DA systems, several studies have also explored their use in ensemble DA systems (Szunyogh et al. 2008; Fertig et al. 2009; Stengel et al. 2009, 2013; Miyoshi et al. 2010; Aravequia et al. 2011; Cintineo et al. 2016).

$\mathrm{BC}$ methods typically assume that a linear relationship exists between the OMB departure bias and a given set of predictors. Though previous studies have shown that linear BC methods are able to effectively remove biases from clear-sky satellite observations, these methods are suboptimal if the observation bias varies as a nonlinear function of some predictor. Indeed, Okamoto et al. (2019) found that linear BC predictors obtained from a clear-sky assimilation system and then used during the assimilation of all-sky infrared brightness temperatures did not lead to more accurate analyses or forecasts. They speculated that the lack of improvement may have occurred because the allsky biases were too complex to remove using linear BC predictors. Otkin et al. (2018) showed that nonlinear conditional biases are more likely to occur in cloud-affected observations, which necessitates the development of $\mathrm{BC}$ methods that can capture complex error patterns in all-sky observations. Their study also showed that cloud-sensitive predictors, such as the cloud-top height $(\mathrm{CTH})$ or the brightness temperatures themselves, are most effective at removing biases from all-sky infrared observations. In this study, we build upon the work of Otkin et al. (2018) by assessing the ability of linear and nonlinear BC predictors in the context of all-sky infrared brightness temperature assimilation to improve short-range (1-h) forecasts in an ensemble DA system. The paper is organized as follows. The DA framework is described in section 2, with assimilation results using different linear and nonlinear BC predictors presented in section 3. Conclusions and a discussion are presented in section 4 .

\section{Experimental design}

\section{a. SEVIRI satellite datasets}

The DA experiments performed during this study employed all-sky infrared brightness temperatures from the SEVIRI sensor on board the Meteosat Second Generation satellite, along with CTH retrievals provided by the EUMETSAT Nowcasting Satellite Applications Facility. The SEVIRI sensor observes the top-of-atmosphere radiances across 12 visible and infrared spectral bands, with a nadir resolution of $3 \mathrm{~km}$ for all infrared bands (Schmetz et al. 2002). This study focuses on the assimilation of clear and cloudy-sky brightness temperatures from the $6.2-\mu \mathrm{m}$ band sensitive to clouds and water vapor in the upper troposphere. Under clear-sky conditions, the weighting function for this band peaks near $350 \mathrm{hPa}$ for a standard midlatitude atmosphere; however, it will shift upward and become truncated near the cloud top when clouds are present due to increased scattering. It will also peak at a higher (lower) atmospheric level if more (less) water vapor is present in the middle and upper troposphere. The dual sensitivity of this band to clouds and water vapor is advantageous for DA applications because increasing moisture and increasing cloud optical thickness influence the infrared brightness temperatures in a similar way. The resultant smoother dependence between water in its vapor and condensed (cloud) states will generally lead to more Gaussian statistics than would occur with an infrared atmospheric window band that has little or no sensitivity to water vapor.

As will be discussed in section 3, CTH retrievals derived from SEVIRI observations were used as one of the $\mathrm{BC}$ predictors during the DA experiments. With this dataset, the CTH is estimated for each satellite pixel by first computing a simulated clear-sky $10.8-\mu \mathrm{m}$ brightness temperature using the Radiative Transfer for TOVS (RTTOV) radiative transfer model (Saunders et al. 1999) and temperature and water vapor profiles from the global NWP model run at the DWD (Majewski et al. 2002). An opaque cloud is then inserted into the atmospheric profile at successively higher levels until the difference between the observed and simulated brightness temperatures is minimized (Derrien and Le Gleau 2005). The CTH retrievals have a nominal vertical resolution of $200 \mathrm{~m}$; however, their uncertainty is larger for semitransparent clouds (Le Gleau 2016). The retrieved CTH for a given satellite pixel is assumed to be spatially homogeneous across the entire pixel. To minimize the impact associated with spatially correlated errors in the full-resolution datasets (3-km at nadir), the CTH retrievals and SEVIRI brightness temperatures were horizontally thinned by a factor of five in the meridional 
and zonal directions. This reduces their horizontal resolution to $\sim 20-25 \mathrm{~km}$ across the model domain, which is $\sim 8$ times coarser than the resolution of the NWP model employed during this study.

\section{b. KENDA data assimilation system}

Ensemble DA experiments were performed using a research version of the regional-scale KENDA system (Schraff et al. 2016) used at the DWD. A major development focus of KENDA in recent years has been the inclusion of cloud- and precipitation-sensitive observations that can be used to constrain the cloud and thermodynamic fields in convection-resolving models. KENDA employs a local ensemble transform Kalman filter (Hunt et al. 2007) during the analysis step and the Consortium for Small-Scale Modeling (COSMO) NWP model (Baldauf et al. 2011) during the forecast step. All of the DA experiments were run on the COSMO-DE domain covering Germany and parts of surrounding countries with $2.8-\mathrm{km}$ horizontal resolution. With this version of KENDA, the lateral boundary conditions were obtained at hourly intervals from the COSMO-EU domain run at the DWD, which in turn was driven by lateral boundary conditions from the global Icosahedral nonhydrostatic (ICON) model (Zangl et al. 2015). The COSMO-DE domain contains 50 terrain-following vertical layers, with the model top located near $22 \mathrm{~km}$ (about $40 \mathrm{hPa}$ ).

The COSMO model includes prognostic variables for atmospheric temperature, pressure, horizontal and meridional wind components, and the mixing ratios for water vapor, cloud water, rainwater, ice, snow, and graupel. Cloud microphysical processes are handled using a simplified version of the double-moment Seifert and Beheng (2001) microphysics scheme that was reduced to a single-moment scheme for computational purposes, whereas the parameterization of cloud formation and decay processes is based on Lin et al. (1983). Though deep convection is explicitly resolved on the COSMO-DE domain, a simplified version of the Tiedtke (1989) mass-flux scheme is used to parameterize shallow convection. Atmospheric turbulence is predicted using the 2.5-order turbulent kinetic energy scheme developed by Raschendorfer (2001). A $\delta$-twostream radiative transfer method is used to update atmospheric heating rates due to radiative effects at 15-min intervals (Ritter and Geleyn 1992).

The DA experiments employed a 40-member ensemble, along with a deterministic run that is initialized by applying the Kalman gain matrix from the assimilation update to the deterministic model background. The ensemble and deterministic runs were initialized at 0000 UTC 28 May 2014 and then updated at hourly intervals during a 3-day period. Modelequivalent brightness temperatures for the SEVIRI $6.2-\mu \mathrm{m}$ band were computed using version 10.2 of the RTTOV radiative transfer model that includes an enhanced cloud-scattering module that enables the use of cloud hydrometeor profiles located on the NWP model vertical grid (Matricardi 2005; Hocking et al. 2011). Vertical profiles of fractional cloud cover and ice and liquid water contents used to compute the cloudy-sky brightness temperatures were obtained using COSMO model output and empirical relationships developed by Kostka et al. (2014). The maximum-random cloud overlap scheme (Raisanen 1998) was used, with the ice crystals assumed to have a hexagonal shape and the effective particle diameters computed using the McFarquhar et al. (2003) method.

SEVIRI $6.2-\mu \mathrm{m}$ brightness temperatures, along with radiosonde, surface, wind profiler, and aircraft observations, were actively assimilated at hourly intervals during each DA experiment. The corresponding model equivalents were computed at the exact observation times through inclusion of the various observation operators within the COSMO model. Covariance inflation values were computed at each grid point using a combination of the relaxation to prior perturbations approach described by Zhang et al. (2004) and multiplicative inflation based on Anderson and Anderson (1999). Covariance localization was performed by using only those observations located within a specified horizontal radius of a given analysis point. An adaptive horizontal localization radius was used for the conventional observations (Perianez et al. 2014); however, it was set to $35 \mathrm{~km}$ for the all-sky SEVIRI brightness temperatures given their uniform data coverage. The vertical localization scale was set to 0.7 in logarithm of pressure for the brightness temperatures, with the localization height determined using the peak of the satellite weighting function for the simulated brightness temperature from the deterministic run. The observation error was set to $4 \mathrm{~K}$ for the all-sky brightness temperatures, similar to that used in Otkin (2012b) and Cintineo et al. (2016). Though it may have been advantageous to use a clouddependent observation error model, that is beyond the scope of the current study.

\section{c. Nonlinear bias correction method}

Systematic biases were removed from the satellite observations using the NBC method developed by Otkin et al. (2018). This method uses a Taylor series polynomial expansion of the OMB departures for a given satellite band to remove linear and nonlinear conditional biases from the observations prior to their assimilation. A brief overview of the NBC method is 
provided here, with the reader referred to Otkin et al. (2018) for a more detailed description. To begin, the OMB departure vector is defined as:

$$
d \mathbf{y}=\mathbf{y}-H(\mathbf{x}),
$$

where $\mathbf{y}$ and $H(\mathbf{x})$ are vectors containing the observed and model-equivalent brightness temperatures, respectively; and $H$ is the observation operator that is used to convert the NWP model first guess fields into simulated brightness temperatures. If we assume that any biases present in the OMB departures can be described by a real function $f(z)$ that is infinitely differentiable around a real number $c$, Eq. (1) can be decomposed into an $N$-order Taylor series polynomial expansion. A representative example in which a single predictor is used to identify biases in a given set of observations using a third-order expansion is shown in Eq. (2):

$d \mathbf{y}=\left\{b_{0}+b_{1}\left[z^{(i)}-c\right]+b_{2}\left[z^{(i)}-c\right]^{2}+b_{3}\left[z^{(i)}-c\right]^{3}\right\}_{i=1, \ldots, m}$,

where $m$ is the number of observations, $z^{(i)}$ is the predictor value for the $i$ th observation, $b_{n}$ are the $0 . . n$th $\mathrm{BC}$ coefficients, and $c$ is a constant that can be set to any value. The $(i=1, \ldots, m)$ notation outside the parentheses indicates that the Taylor series terms are computed separately for each element of the observation departure vector. In this example, the first two terms on the right-hand side represent the constant and linear bias components, whereas the last two terms represent the nonlinear second-order (quadratic) and third-order (cubic) components.

Equation (2) can be rewritten in matrix notation as $d \mathbf{y}=\mathbf{A b}$, where $\mathbf{A}$ is an $m \times n$ matrix containing the $n$ Taylor series terms for each observation and $\mathbf{b}$ is an $n \times 1$ vector containing the BC coefficients. This is an overdetermined system of $m$ linear equations in $n$ unknown coefficients because $m>n$. The BC coefficients that best fit the set of equations can be identified by solving the quadratic minimization problem, which, after adding a Tikhonov regularization term $(\alpha I)$ to improve its conditioning, leads to:

$$
\mathbf{b}=\left(\alpha I+\mathbf{A}^{\mathrm{T}} \mathbf{A}\right)^{-1} \mathbf{A}^{\mathrm{T}} \mathbf{d y},
$$

where $\left(\alpha I+\mathbf{A}^{\mathrm{T}} \mathbf{A}\right)$ is a symmetric, $n \times n$ square matrix, thereby making it easy to compute its inverse. The Tikhonov regularization term is defined to be a multiple of the identity matrix, which is a standard approach when solving inverse problems (Nakamura and Potthast 2015). The constant $\alpha$ was set to a very small value $\left(10^{-9}\right)$ following the results of Otkin et al. (2018).
For this study, the BC coefficients for the SEVIRI $6.2-\mu \mathrm{m}$ band were updated during each assimilation cycle using only the observation departure statistics accumulated during the previous hour. This approach was used rather than accumulating statistics over a longer time period because it allows the BC coefficients to quickly adapt to changes in the cloud field, such as those associated with the diurnal cycle of convection and its impact on cloud properties in the upper troposphere. All of the observation departures for a given assimilation cycle were used to compute the BC coefficients, thereby providing a larger sample size and negating the need to identify cloud-matched observations when determining the coefficients. After calculating the BC coefficients, they were then applied separately to each observation and ensemble member.

\section{Results}

In this section, we assess the ability of all-sky infrared brightness temperatures from the SEVIRI $6.2-\mu \mathrm{m}$ band to improve short-range forecasts when assimilated in an ensemble DA system after using various BC predictors to remove biases from the observations. Figure 1 shows the evolution of the upper-level cloud and water vapor fields during the 3-day assimilation period, as depicted by the observed SEVIRI $6.2-\mu \mathrm{m}$ brightness temperatures. At the start of the period, an extensive area of cold, upper-level clouds associated with widespread precipitation extended from northwest-to-southeast across the domain (Fig. 1a). As this weather feature slowly moved southward and weakened during the next two and a half days, the lower brightness temperatures indicative of optically thick clouds were steadily replaced by higher brightness temperatures as the clouds became optically thinner and their spatial extent lessened. A small area of clear skies across the southwestern part of the domain was shunted southward during this time period, with a much larger area of clear skies developing behind the departing weather feature (Fig. 1e). Within these clear-sky areas, the highest brightness temperatures are associated with the driest conditions in the upper troposphere. Overall, the synopsis presented in this section shows that there were a wide range of cloud and water vapor conditions in the upper troposphere that together support a realistic assessment of the impacts of the infrared brightness temperatures and bias predictors in the assimilation system.

\section{a. Assessing the impact of nonlinear bias corrections}

Prior work by Otkin et al. (2018) found that it was necessary to use nonlinear $\mathrm{BC}$ predictors to remove cloud-dependent biases from passively monitored 

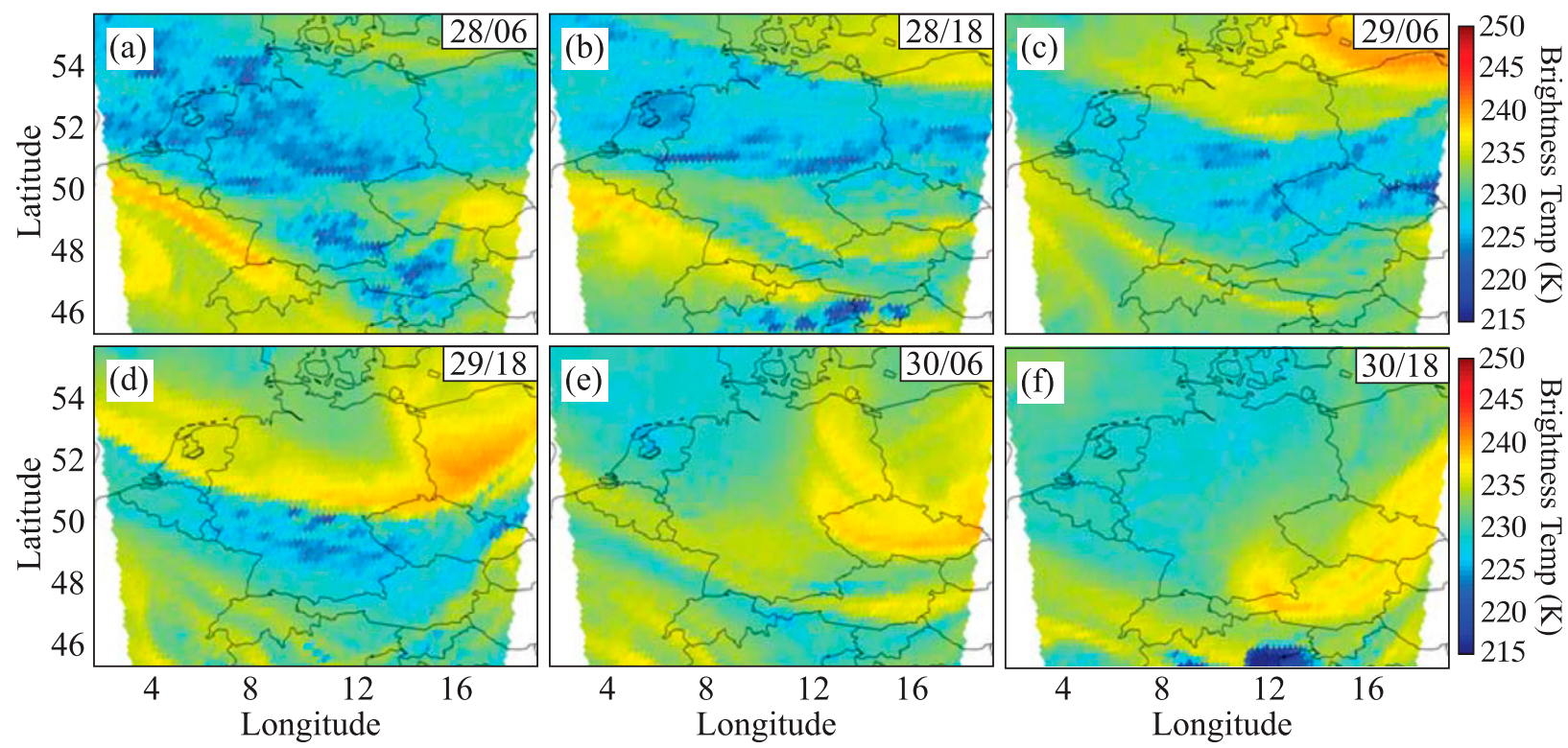

FIG. 1. Observed SEVIRI 6.2- $\mu \mathrm{m}$ brightness temperatures (K) valid at (a) 0600 UTC 28 May, (b) 1800 UTC 28 May, (c) 0600 UTC 29 May, (d) 1800 UTC 29 May, (e) 0600 UTC 30 May, and (f) 1800 UTC 30 May 2014.

all-sky infrared brightness temperatures. Here, we extend their results by examining the impact of nonlinear BC predictors in cycled DA experiments where all-sky $6.2-\mu \mathrm{m}$ brightness temperatures are actively assimilated. In particular, experiments are performed where the observation bias is removed using a 0th (constant), first- (linear), second- (quadratic), or third- (cubic) order Taylor series polynomial expansion of the OMB departures when the observed cloud-top height is used as the bias predictor. To provide complete domain coverage, satellite pixels identified as clear in the EUMETSAT CTH product were assigned a height equal to the model terrain elevation. These four experiments are hereafter referred to as OBSCTH-0TH, OBSCTH-1ST, OBSCTH-2ND, and OBSCTH-3RD, respectively. Results from these experiments are then compared to two baseline experiments in which the allsky infrared observations are either not assimilated (No-Assim), or are actively assimilated, but without using $\mathrm{BC}$ (No-BC). The impact of the $\mathrm{BC}$ predictors is assessed using $\mathrm{OMB}$ departure statistics from the prior ensemble mean analyses accumulated at hourly intervals during the $72-\mathrm{h}$ assimilation period. The prior analyses are used here to provide a measure of the observation impact on short-range (1-h) forecasts.

\section{1) BRIGHTNESS TEMPERATURE BIAS CORRECTION STATISTICS}

To assess how the $\mathrm{BC}$ changes in relation to use of linear and nonlinear predictors, Fig. 2 shows the $2 \mathrm{D}$ probability distribution of $\mathrm{OMB}$ departures for the
6.2- $\mu \mathrm{m}$ brightness temperatures from the No-Assim experiment (Fig. 2a), along with the corresponding BC distributions for each DA experiment. All of the distributions are plotted as a function of the observed 6.2- $\mu \mathrm{m}$ brightness temperatures. The magenta line in each panel denotes the mean of the entire distribution, whereas the shorter black lines depict the conditional mean in each column. Inspection of Fig. 2a reveals that, though the mean bias during the No-Assim experiment is relatively small $(-0.76 \mathrm{~K})$, the conditional biases exhibit an asymmetrical arch-shaped pattern that is a nonlinear function of the observed brightness temperatures. The conditional biases are close to zero for brightness temperatures near $235 \mathrm{~K}$, and remain small for brightness temperatures $>230 \mathrm{~K}$; however, they become progressively more negative for lower brightness temperatures. The large negative biases for the lowest brightness temperatures indicate that the COSMO model forecasts are deficient in upper-level clouds or that there are biases in the RTTOV model used to compute the modelequivalent brightness temperatures. Regardless, assimilation of observations with such large biases could degrade the performance of the DA system. The simplest option is to exclude these observations, however, that is not ideal because they still contain valuable information about random errors in the cloud field if the biases can be removed.

Inspection of the corrections applied to the infrared observations during the active DA experiments (Figs. 2b-e) reveals that the mean BC is similar for all experiments despite the $2 \mathrm{D}$ distributions having very 
different shapes. This occurs because the mean BC is most strongly influenced by the mean bias in the full set of OMB departures (Fig. 2a) and by the tendency for larger corrections for the lower brightness temperatures to be offset by smaller corrections for the higher brightness temperatures. Because the single bias predictor in the OBSCTH-0TH experiment (Fig. 2b) is only able to remove the mean bias during a given assimilation cycle, it has a narrower $\mathrm{BC}$ distribution than the other experiments. There is still some spread in the corrections during this experiment because the $\mathrm{BC}$ varies for each assimilation cycle due to changes in the prevailing atmospheric conditions. The constant corrections, however, are not optimal because they are unable to account for the large variations in the conditional biases across the OMB distribution (Fig. 2a). In contrast, more accurate corrections are obtained through application of the linear bias predictor during the OBSCTH1ST experiment (Fig. 2c), as evidenced by the smaller (larger) BC for brightness temperatures greater (less) than $230 \mathrm{~K}$. The corrections for the lower brightness temperatures become even larger during the OBSCTH2ND and OBSCTH-3RD experiments (Figs. 2d,e) because the additional nonlinear predictors are able to remove more of the conditional biases at those temperatures (Fig. 2a). Overall, these results indicate that the OBSCTH-2ND and OBSCTH-3RD experiments provide more accurate $\mathrm{BC}$ in the presence of complex nonlinear bias patterns.

\section{2) BRIGHTNESS TEMPERATURE ERROR TIME SERIES}

The evolution of the $6.2-\mu \mathrm{m}$ brightness temperature root-mean-square error (RMSE) and bias during the 3-day assimilation period is shown in Fig. 3. The error statistics were computed using the ensemble mean brightness temperatures from the prior analyses for each assimilation cycle. Note that the bias is nonzero for all of the experiments because the statistics were computed using output from 1-h forecasts and prior to bias-correcting the satellite observations. Overall, there is a large diurnal cycle in the error statistics, with the largest RMSE and negative biases occurring during the daytime (0900-1800 UTC), followed by smaller errors at night. This error pattern is consistent with a lack of lower brightness temperatures during the afternoon when the deficiency in upper-level clouds associated with deep convection is most prominent (not shown). The large diurnal differences in the bias also illustrate why it is advantageous to compute the $\mathrm{BC}$ coefficients using observations from a single assimilation cycle because accumulation of OMB departures over longer time periods would obscure these important differences and therefore make the $\mathrm{BC}$ method less effective.

Inspection of the error time series reveals that the bias and RMSE are smallest during the No-BC experiment, which indicates that larger improvements are realized in the forecast cloud field when BC is not applied to the all-sky brightness temperatures. As will be shown in the next section, however, the improved fits to the satellite observations during the No-BC experiment do not translate into smaller errors for conventional observations that are not sensitive to clouds. Compared to the No-Assim experiment, the four experiments in which bias-corrected satellite observations were assimilated had similar biases, but much smaller RMSE, with values approaching those obtained during the No-BC experiment. The simultaneous large reductions in RMSE and small changes in bias demonstrate that even though the bias-corrected observations are unable to substantially reduce the bias, it is still possible to use them to fix random errors in the cloud and water vapor fields. Moreover, though there is a trend toward lower RMSE in all of the experiments during the 3-day assimilation period due to a decrease in upper-level clouds (Fig. 1), this decrease in RMSE is larger for the experiments where infrared observations are assimilated. This result provides further evidence that the all-sky infrared brightness temperatures are able to improve the cloud field in the 1-h forecasts regardless of whether or not BC is applied to them prior to their assimilation.

\section{3) CONVENTIONAL OBSERVATION ERROR ANALYSIS}

To assess the impact of the nonlinear bias predictors on the thermodynamic and kinematic fields, Fig. 4 shows vertical profiles of RMSE for air temperature, relative humidity, and the zonal and meridional wind components computed using radiosonde observations accumulated over the 3-day assimilation period and binned into 100-hPa layers. For each variable, RMSE profiles are shown for the two baseline experiments (No-Assim and No-BC), followed by vertical profiles showing the percentage changes in RMSE for the remaining experiments computed with respect to each of the baseline experiments. This approach was used to make it easier to assess the impact of the bias predictors, while still being able to show the baseline error profiles. Negative (positive) changes mean that assimilation of the all-sky infrared observations decreased (increased) the errors relative to a given baseline experiment and therefore improved (degraded) the prior analysis fits to the radiosonde observations. Figure 5 shows the corresponding profiles of observation bias for each experiment. Only raw error profiles are shown for this metric because 


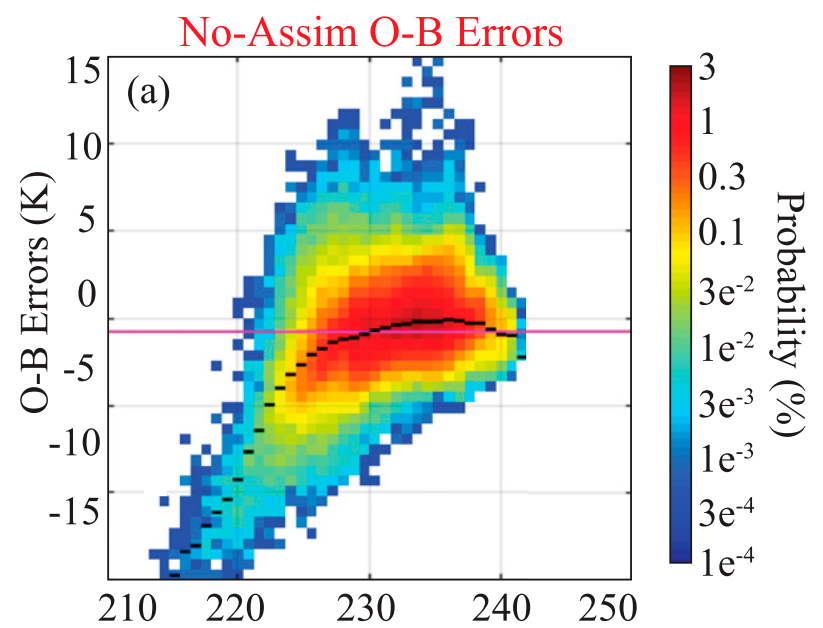

Observed Bright Temp (K)

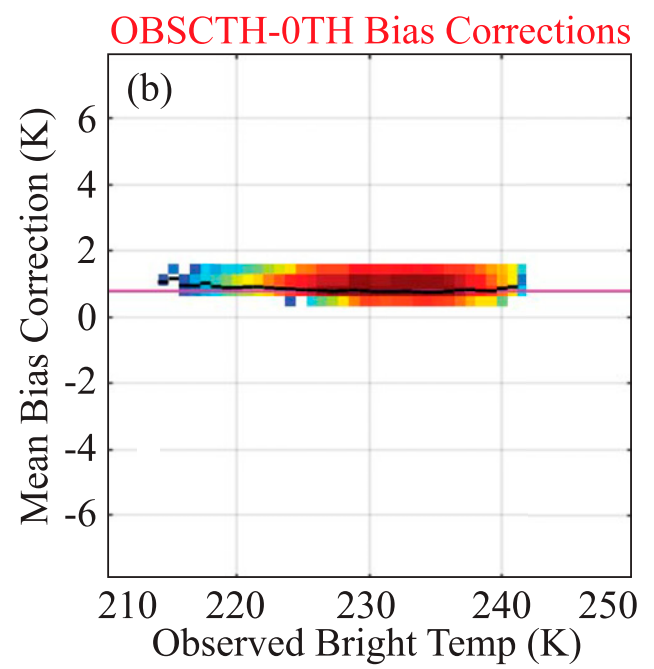

OBSCTH-1ST Bias Corrections

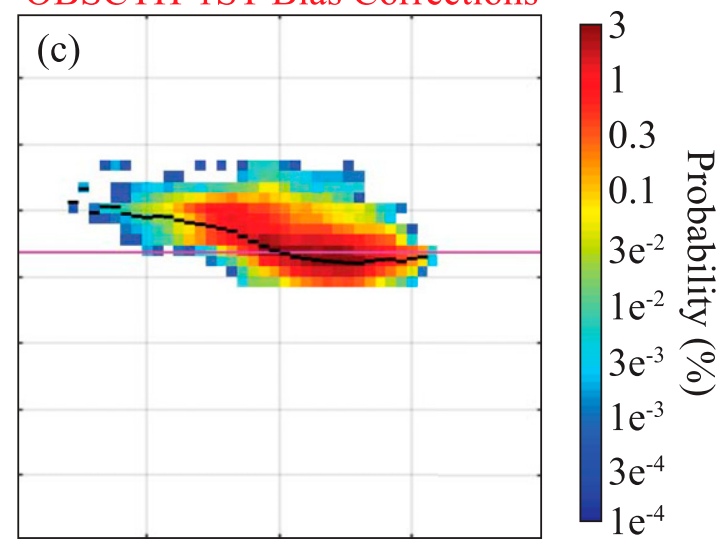

OBSCTH-2ND Bias Corrections
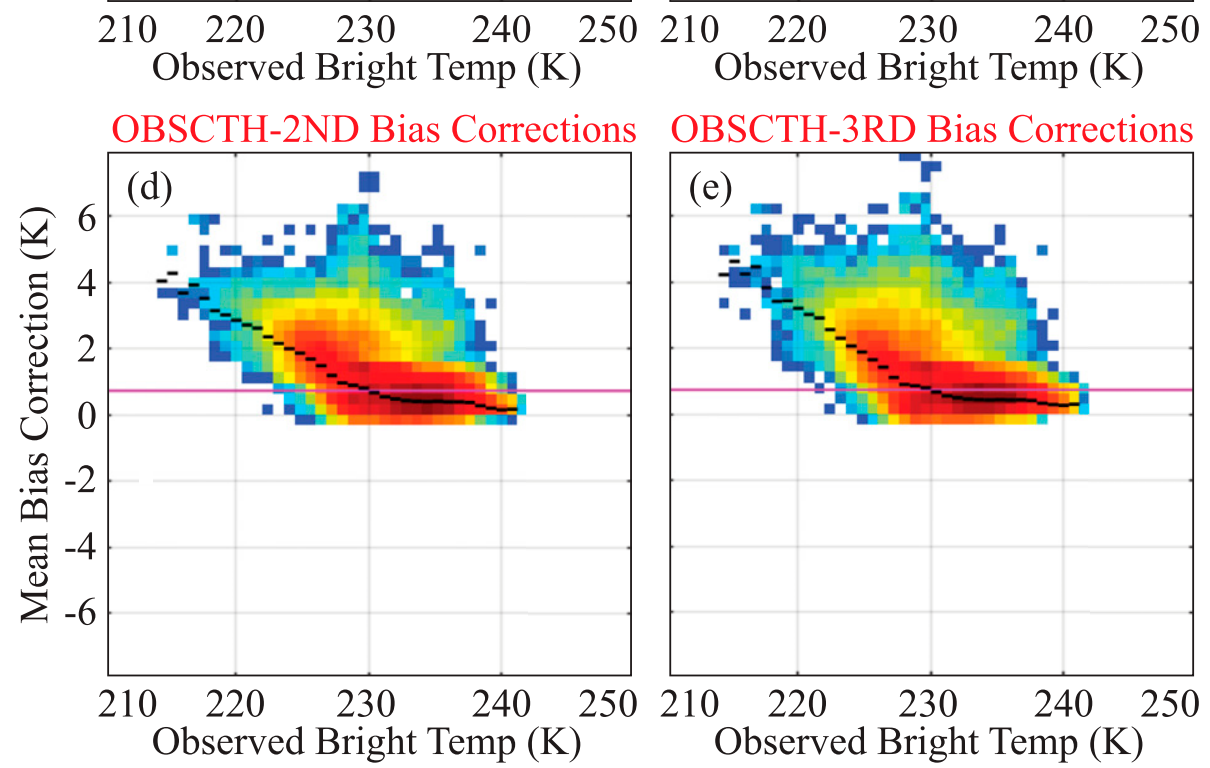

Observed Bright Temp (K)
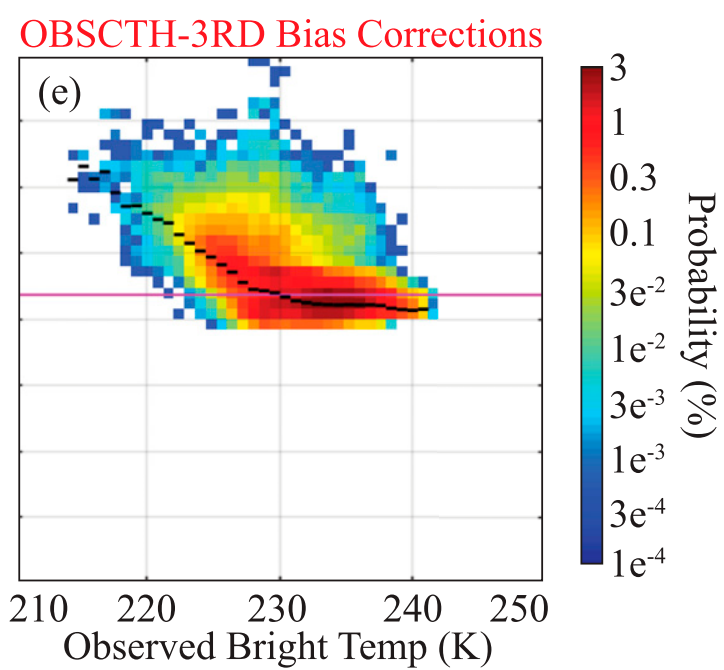

FIG. 2. (a) Probability distribution of SEVIRI 6.2- $\mu \mathrm{m}$ observation-minus-background (O-B) brightness temperature departures $(\mathrm{K})$ for the No-Assim experiment plotted as a function of the observed 6.2- $\mu \mathrm{m}$ brightness temperatures (K). (b)-(e) Probability distributions of SEVIRI $6.2 \mu \mathrm{m}$ ensemble mean brightness temperature bias corrections (K) for the OBSCTH-0TH, OBSCTH-1ST, OBSCTH-2ND, and OBSCTH-3RD experiments 

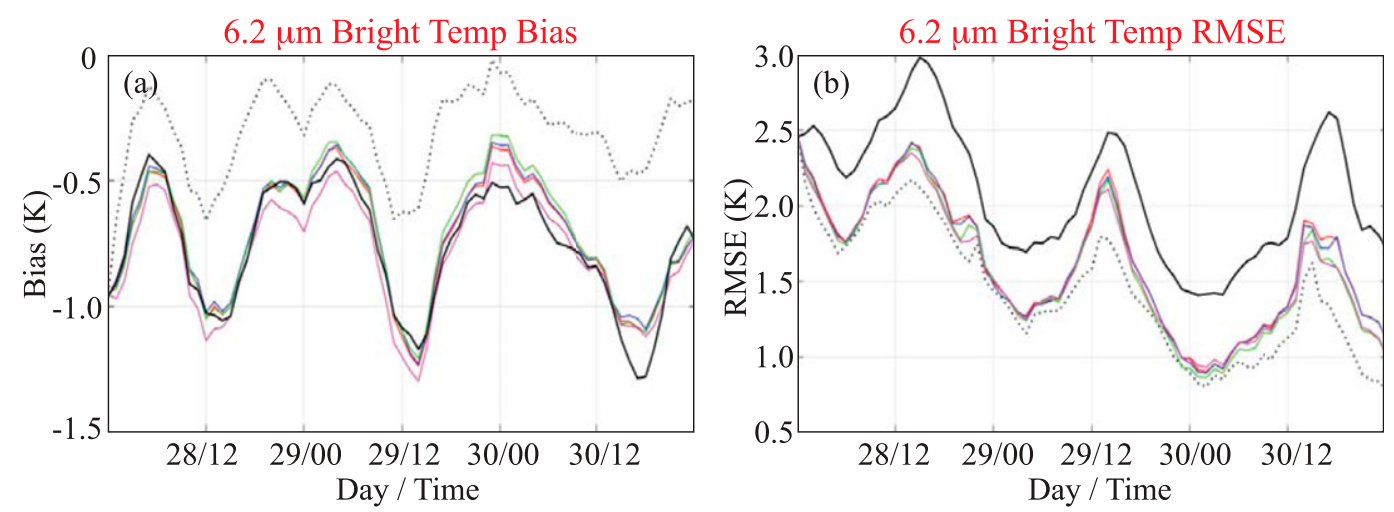

FIG. 3. Time series showing the evolution of the SEVIRI 6.2- $\mu \mathrm{m}$ brightness temperature (a) bias (K) and (b) rootmean-square error (RMSE; K) computed using the ensemble mean prior analysis at hourly intervals from 0000 UTC 28 May to 0000 UTC 31 May 2014. Results are shown for the No-BC (dashed black line), OBSCTH-3RD (red line), OBSCTH-2ND (blue line), OBSCTH-1ST (green line), OBSCTH-0TH (magenta line), and No-Assim (solid black line) experiments.

small biases in the baseline experiments make the percentage changes difficult to evaluate.

Comparison of the temperature RMSE profiles for the baseline experiments reveals that the errors are up to $2 \%$ smaller (larger) in the upper (lower) troposphere when the all-sky observations are assimilated during the No-BC experiment (Fig. 4b). The RMSE and bias for the radiosonde temperatures were smaller below $400 \mathrm{hPa}$ when the brightness temperature biases were removed during the OBSCTH experiments; however, the errors increased by several percent above this level (Figs. 4c, 5a). Because the largest BC is generally applied to lower brightness temperatures associated with clouds in the upper troposphere (e.g., Fig. 2), the larger errors near and above the tropopause indicate that removal of the brightness temperature bias may actually lead to some degradation in the fits to the radiosonde temperatures. The larger temperature errors occur during all of the OBSCTH experiments, however, which suggests that they may be related to removal of the mean brightness temperature bias rather than to removal of the conditional biases. It is also possible that some of the cloud and water vapor information from the all-sky satellite observations is being incorrectly aliased onto the temperature field. Further work is necessary to identify the cause of the larger temperature errors between 300 and $100 \mathrm{hPa}$.

For the relative humidity observations, the RMSE from the baseline experiments is relatively small near the surface, but increases rapidly to over $20 \%$ by $800 \mathrm{hPa}$. It then remains large in the middle troposphere before slowly decreasing with height in the upper troposphere (Fig. 4d). The bias profiles from the baseline experiments likewise indicate that the model background is too dry below $800 \mathrm{hPa}$, but too moist above this level (Fig. 5b). When all-sky brightness temperatures are assimilated during the No-BC experiment, the RMSE increases throughout most of the vertical profile (Fig. 4e), and the negative biases become even larger in the upper troposphere (Fig. 5b). Indeed, the relative humidity errors are larger in the No-BC experiment than they are in the No-Assim experiment despite the fact that the infrared observations are strongly sensitive to water vapor in the upper troposphere. As discussed previously, the negative conditional biases for brightness temperatures $<230 \mathrm{~K}$ indicate that the model background is deficient in upper-level clouds (Fig. 2a). Thus, it appears that trying to add clouds more forcefully through assimilation of the non-bias-corrected observations leads to an incorrect aliasing of cloud information onto the water vapor field. Instead of increasing the cloud condensate in response to the negative OMB departures, the assimilation instead adds more water vapor to the model analyses. In contrast, both the RMSE and bias are greatly reduced when $\mathrm{BC}$ is applied to the infrared observations during the OBSCTH experiments (Figs. 4f, 5b). When combined with the brightness temperature statistics shown in Fig. 3, this demonstrates that

\footnotetext{
plotted as a function of the observed $6.2-\mu \mathrm{m}$ brightness temperatures (K). Data were accumulated at hourly intervals during a 72-h period from 0000 UTC 28 May to 0000 UTC 31 May 2014. The horizontal purple lines show the (a) mean O-B departure or the (b)-(e) mean bias correction, whereas the black line segments depict the (a) conditional O-B bias or the (b)-(e) mean bias correction in each column.
} 
Temperature

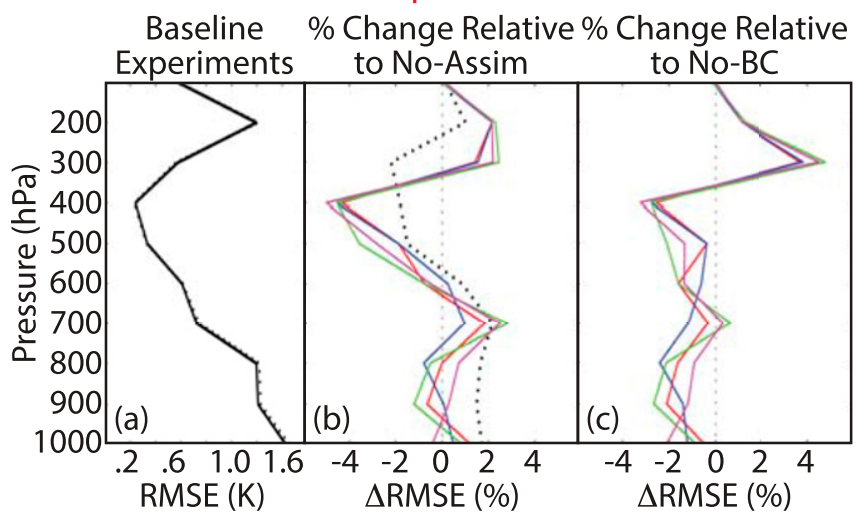

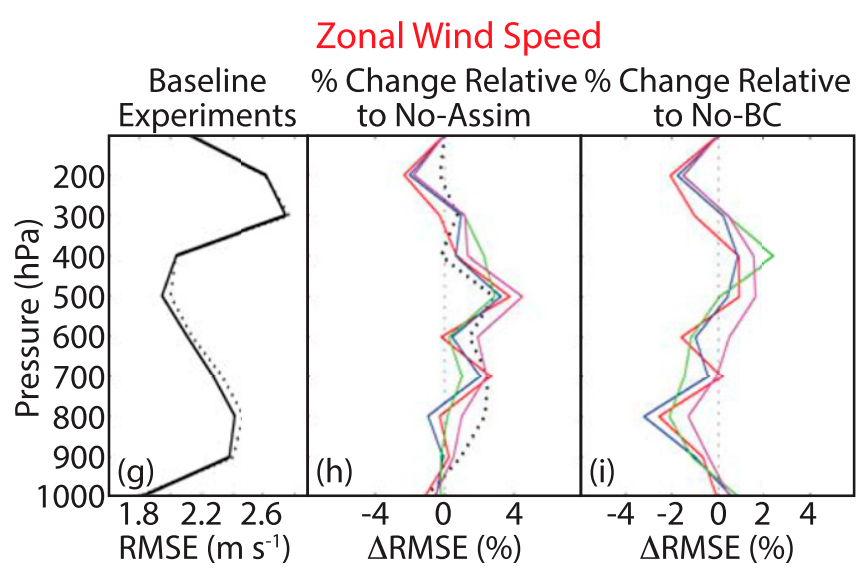

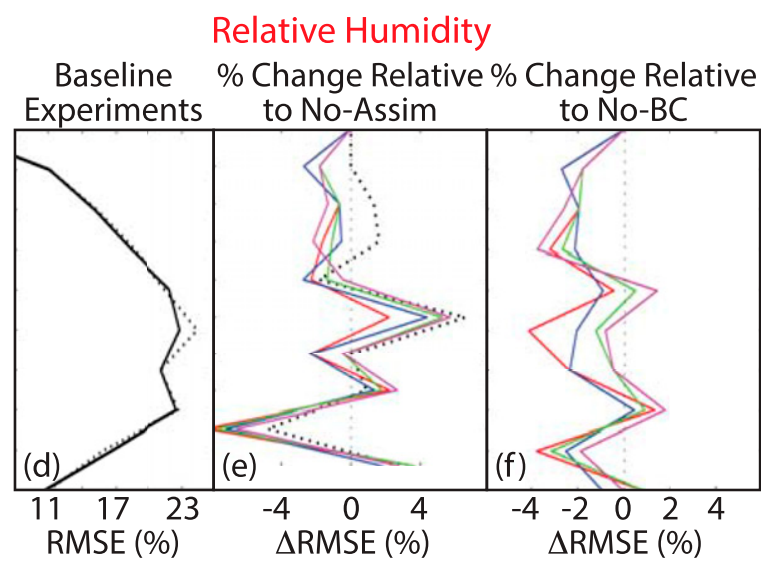

Meridional Wind Speed

Baseline \% Change Relative \% Change Relative

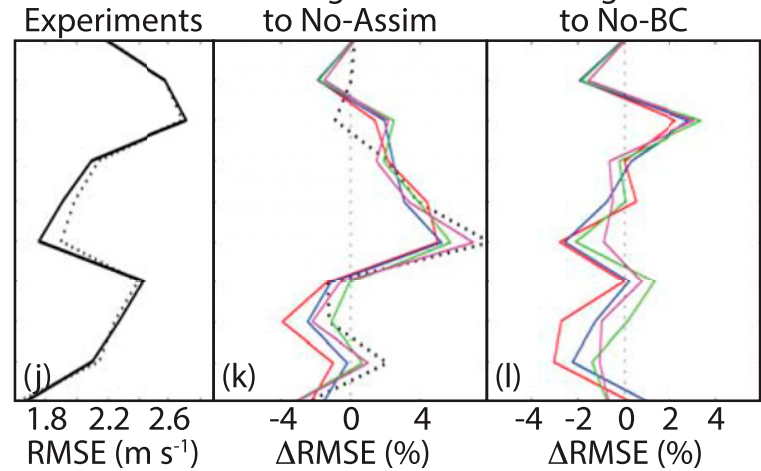

FIG. 4. (a) Vertical profiles of temperature root-mean-square error (RMSE; K) from the No-Assim (black) and No-BC experiments (dashed black), with percentage changes in RMSE for the OBSCTH-3RD (red), OBSCTH-2ND (blue), OBSCTH-1ST (green), and OBSCTH-0TH (magenta) experiments relative to the (b) No-Assim and (c) No-BC experiments. (d)-(f) As in (a)-(c), but for showing vertical profiles of relative humidity RMSE (\%). (g)-(i) As in (a)-(c), but for showing vertical profiles of zonal wind speed RMSE (m s ${ }^{-1}$ ). (j)-(l) As in (a)-(c), but for showing vertical profiles of meridional wind speed RMSE $\left(\mathrm{m} \mathrm{s}^{-1}\right)$. The error profiles were computed using data from the prior analyses over a 3-day period from 0000 UTC 28 May to 0000 UTC 31 May 2014.

bias-correcting the all-sky infrared observations retains some cloud information during the assimilation while also improving the water vapor field.

For the zonal and meridional wind observations, the RMSE profiles from the baseline experiments have a sinusoidal appearance characterized by the largest errors in the lower and upper troposphere and smaller errors in the midtroposphere (Figs. $4 \mathrm{~g}, \mathrm{k}$ ). The biases in the baseline experiments are generally $<0.2 \mathrm{~m} \mathrm{~s}^{-1}$, with the largest biases occurring near 600 and $700 \mathrm{hPa}$ for the zonal and meridional wind components, respectively (Figs. 5c,d). The RMSE generally increases, especially for the meridional wind component, when the satellite observations are assimilated during the No-BC experiment (Figs. 4h,k). The wind errors are slightly reduced, however, when $\mathrm{BC}$ is applied to the infrared brightness temperatures during the OBSCTH experiments (Figs. 4i,1). Even so, it is evident that assimilation of the all-sky observations leads to a slightly negative impact on the midtropospheric winds and only a neutral to slightly positive impact in the lower troposphere and near the tropopause.

To more clearly assess the impact of the nonlinear $\mathrm{BC}$ predictors on each variable, summary statistics were computed using all of the radiosonde observations during the $72-\mathrm{h}$ assimilation period. Table 1 shows the percentage changes in RMSE and bias for each OBSCTH experiment relative to the No-BC experiment. Overall, it is evident that bias-correcting the infrared brightness temperatures improves the quality of the model background fields. The largest improvements (negative values) occur for the relative humidity field, with the bias reduced by at least $25 \%$ during each experiment. Smaller improvements occurred for the other variables. Comparison of the OBSCTH experiments reveals that there is a distinct advantage to using higherorder $\mathrm{BC}$ terms to remove the bias from the all-sky brightness temperatures. For example, the RMSE for 

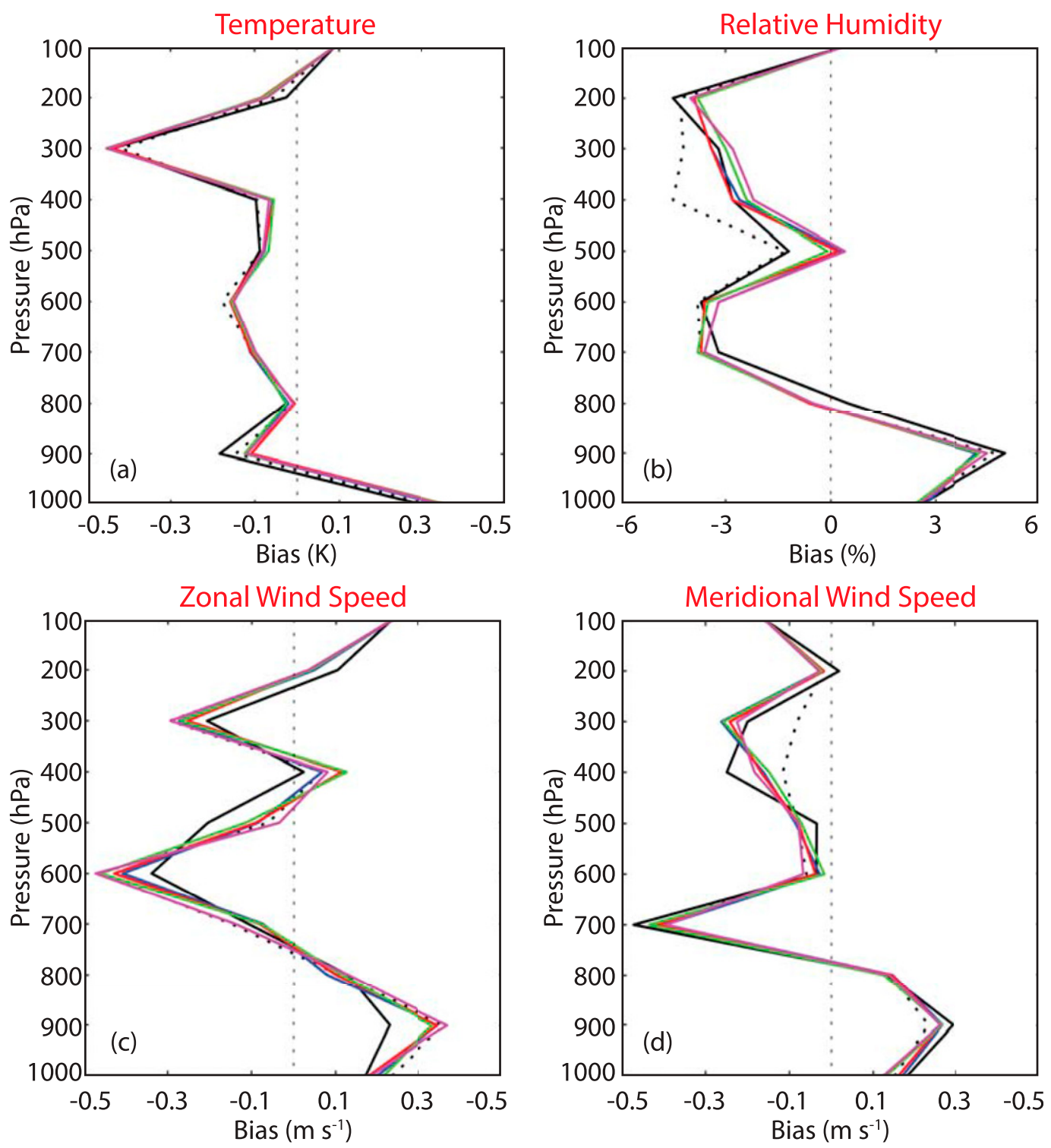

FIG. 5. Vertical profiles of (a) temperature bias (K), (b) relative humidity bias (\%), (c) zonal wind speed bias $\left(\mathrm{m} \mathrm{s}^{-1}\right)$, and (d) meridional wind speed bias $\left(\mathrm{m} \mathrm{s}^{-1}\right)$ for the No-Assim (solid black), No-BC (dashed black), OBSCTH-3RD (red), OBSCTH-2ND (blue), OBSCTH-1ST (green), and OBSCTH-0TH (magenta) experiments. The error profiles were computed using data from the prior analyses over a 3-day period from 0100 UTC 28 May to 0000 UTC 31 May 2014.

the relative humidity and wind observations steadily decrease as the $\mathrm{BC}$ predictor increases from the zeroth (OBSCTH-0TH) to third (OBSCTH-3RD) order. The impact of the higher-order $\mathrm{BC}$ terms is less consistent for temperature and for the relative humidity bias; however, the errors are still smaller than occurred during the No-BC experiment. Together, the results presented in this section have shown that it is necessary to bias correct the infrared observations prior to their assimilation and that it is generally beneficial to include nonlinear BC predictors. This was demonstrated by the tendency for the higher-order predictors to have a neutral-to-positive impact on the temperature and wind fields, while also improving the cloud and water vapor fields.

\section{b. Assessing the impact of different bias predictor variables}

In this section, we assess the ability of individual bias predictor variables sensitive to clouds and water vapor, or that depict variations in the satellite zenith angle, to improve the assimilation of all-sky infrared brightness 
TABLE 1. Percentage changes in root-mean-square error (RMSE) and bias for the zonal and meridional wind speed, temperature, and relative humidity for the OBSCTH-0TH, OBSCTH-1ST, OBSCTH-2ND, and OBSCTH-3RD experiments relative to the No-BC experiment. The statistics were computed using all of the radiosonde observations and output from the prior ensemble mean analyses during the 72-h assimilation period.

\begin{tabular}{|c|c|c|c|c|c|c|}
\hline \multirow[b]{2}{*}{ Experiment } & \multirow{2}{*}{$\frac{U}{\mathrm{RMSE}}$} & \multirow{2}{*}{$\frac{V}{\mathrm{RMSE}}$} & \multicolumn{2}{|c|}{$T$} & \multicolumn{2}{|c|}{$\mathrm{RH}$} \\
\hline & & & RMSE & BIAS & RMSE & BIAS \\
\hline OBSCTH-OTH-No-BC & $-0.2 \%$ & $-0.2 \%$ & $-0.1 \%$ & $-4.7 \%$ & $-0.6 \%$ & $-36.2 \%$ \\
\hline OBSCTH-1ST-No-BC & $-0.7 \%$ & $-0.1 \%$ & $-0.3 \%$ & $-3.1 \%$ & $-0.9 \%$ & $-29.1 \%$ \\
\hline OBSCTH-2ND-No-BC & $-0.9 \%$ & $-0.5 \%$ & $-0.3 \%$ & $-5.0 \%$ & $-1.5 \%$ & $-25.6 \%$ \\
\hline OBSCTH-3RD-No-BC & $-1.0 \%$ & $-0.8 \%$ & $-0.2 \%$ & $-1.3 \%$ & $-1.8 \%$ & $-30.2 \%$ \\
\hline
\end{tabular}

temperatures during cycled DA experiments. Based on results from the previous section, all of the experiments employed a third-order polynomial expansion of the OMB departures to remove biases from the satellite brightness temperatures prior to their assimilation. In addition to the OBSCTH-3RD experiment presented in section $3 \mathrm{a}$ (hereafter referred to as BC-OBSCTH), experiments were performed in which the observed SEVIRI $6.2-\mu \mathrm{m}$ brightness temperatures (BC-OBSBT), satellite zenith angle (BC-SATZEN), or $100-700-\mathrm{hPa}$ integrated water content (BC-IWC) were used as the bias predictors. The integrated water content predictor was calculated by converting the water vapor and all cloud hydrometeor mixing ratios in each model layer into millimeters and then integrating over the 100-700-hPa layer. Together, these four predictors were chosen because they were also used during the passive monitoring experiments presented in Otkin et al. (2018). Here, we extend the results of that study by assessing the performance of these bias predictor variables when they are used during active DA experiments.

\section{1) OBservation SPACE DiAgNOSTICS}

Figure 6 shows the evolution of the SEVIRI $6.2-\mu \mathrm{m}$ brightness temperature bias, RMSE, ensemble spread, and consistency ratio (CR) for each experiment during the 3-day assimilation period. The statistics were computed for each assimilation cycle using brightness temperatures from the prior ensemble analyses. The ensemble spread is defined as

$$
\text { Spread }=\sqrt{\left\langle\frac{1}{N-1} \sum_{n=1}^{N}\left[H\left(\mathbf{x}_{n}\right)-\overline{H\left(\mathbf{x}_{n}\right)}\right]^{2}\right\rangle},
$$

where $N$ is the ensemble size, $n$ is the index of a given ensemble member, and $H$ is the observation operator (e.g., RTTOV) used to compute the model-equivalent brightness temperatures. The total ensemble spread is the combination of the observation error ( $\sigma_{\mathrm{obs}}$, set to $4 \mathrm{~K}$ ) and ensemble spread, such that
Total Spread $=\sqrt{\sigma_{\text {obs }}^{2}+\left\langle\frac{1}{N-1} \sum_{n=1}^{N}\left[H\left(\mathbf{x}_{n}\right)-\overline{H\left(\mathbf{x}_{n}\right)}\right]^{2}\right\rangle}$

Finally, the RMSE and total spread are used to calculate the CR, which provides another diagnostic measure of the performance of the assimilation system:

$$
\mathrm{CR}=(\text { Total Spread })^{2} /(\mathrm{RMSE})^{2} .
$$

With the CR, a value of 1 is desired because, in an ideal situation, the total spread should equal the RMSE for each observation type being assimilated. Values greater (less) than 1 indicate that there is too little (too much) ensemble spread and/or that the observation error is larger (smaller) than necessary (Dowell et al. 2004; Aksoy et al. 2009).

Inspection of the time series shows that the smallest RMSE and bias (Figs. 6a,b) occurred during the No-BC experiment, which is not surprising because assimilating non-bias-corrected observations should lead to the largest impact when assessed against themselves. Comparison of the $\mathrm{BC}$ experiments reveals that the BC-SATZEN and BC-IWC experiments have larger biases and RMSEs than the BC-OBSBT and BC-OBSCTH experiments. The larger positive impact of the OBSBT and OBSCTH predictors on these two metrics is consistent with Otkin et al. (2018), who showed that variables sensitive to the $\mathrm{CTH}$ are more effective at identifying biases in all-sky infrared brightness temperatures. The results shown here indicate that using these predictors in active DA experiments also leads to smaller errors in the cloud and water vapor fields in the prior ensemble analyses when assessed using satellite observations.

The ensemble spread (Fig. 6c) generally decreases during the assimilation period due to a transition toward clearer skies and the cumulative impact of the all-sky brightness temperatures on the cloud and water vapor fields. The decrease in ensemble spread 

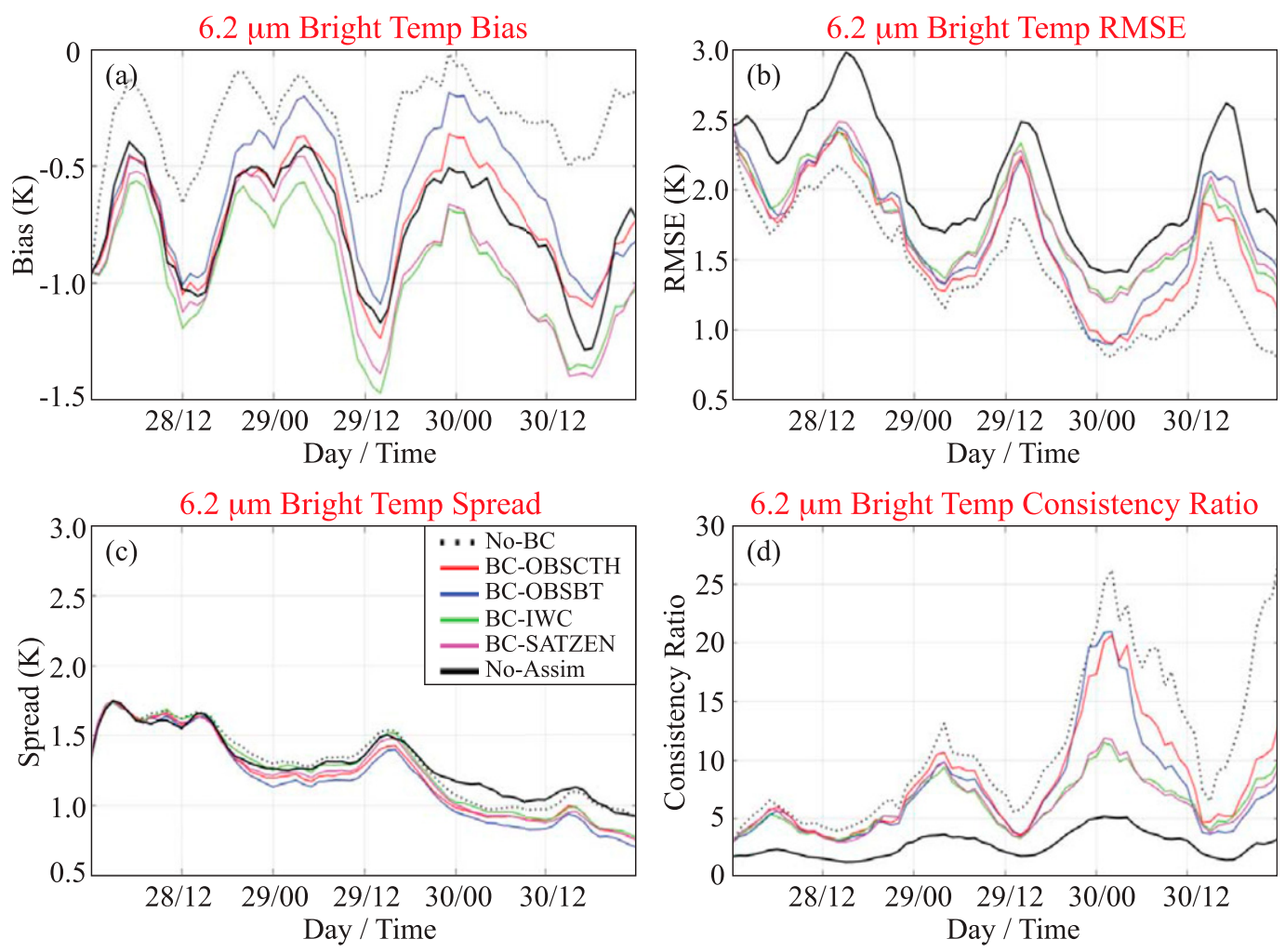

FIG. 6. Time series showing the evolution of the SEVIRI 6.2- $\mu \mathrm{m}$ brightness temperature (a) bias (K), (b) rootmean-square error (RMSE; K), (c) spread (K), and (d) consistency ratio computed using the ensemble mean prior analysis at hourly intervals from 0000 UTC 28 May to 0000 UTC 31 May 2014. Results are shown for the No-BC (dashed black line), BC-OBSCTH (red line), BC-OBSBT (blue line), BC-IWC (green line), BC-SATZEN (magenta line), and No-Assim (solid black line) experiments.

is accompanied by a corresponding increase in the CR (Fig. 6d), which peaks each morning when the RMSE reaches its diurnal minimum. Because the RMSE is smallest during the No-BC, BC-OBSCTH, and BC-OBSBT experiments (Fig. 6b), they also have the largest CRs. The large CR values during all of the active DA experiments reveal that it was suboptimal to employ the same observation error variance for both clear and cloudy-sky observations during the entire assimilation period. Thus, combining an adaptive all-sky observation error model with the BC method would be beneficial; however, that is left for future work. In addition, inspection of rank histograms for each experiment (not shown) revealed that the ensemble spread is too small. This result points toward the need to also develop methods that increase the ensemble spread in cloud hydrometeors because they have the largest impact on the spread in the all-sky infrared brightness temperatures. One potential option would be to use the stochastic parameter perturbations method (Berner et al. 2017) to add perturbations to cloud source/sink terms to account for some of the uncertainty in cloud microphysics schemes. This has been shown to increase the spread in cloudy regions (Griffin et al. 2019, manuscript submitted to Mon. Wea. Rev.).

\section{2) BRIGHTNESS TEMPERATURE BIAS CORRECTION STATISTICS}

To further assess the behavior of each bias predictor, 2D probability distributions of the ensemble mean BCs accumulated at hourly intervals during the 72-h assimilation period are shown for each experiment in Fig. 7. Overall, the BC-OBSBT and BC-OBSCTH experiments have similar distributions characterized by relatively small mean BCs for brightness temperatures $>230 \mathrm{~K}$ and then a strong upward trend in the mean $\mathrm{BC}$ for lower brightness temperatures (Figs. 7a,b). Even so, there are notable differences between these experiments, such as the larger $\mathrm{BC}$ for the lowest brightness temperatures in the BC-OBSBT experiment and the wider vertical distribution for most brightness temperatures in the BC-OBSCTH experiment. The BC patterns for both experiments are flipped compared to the OMB departure distribution from the No-Assim experiment 

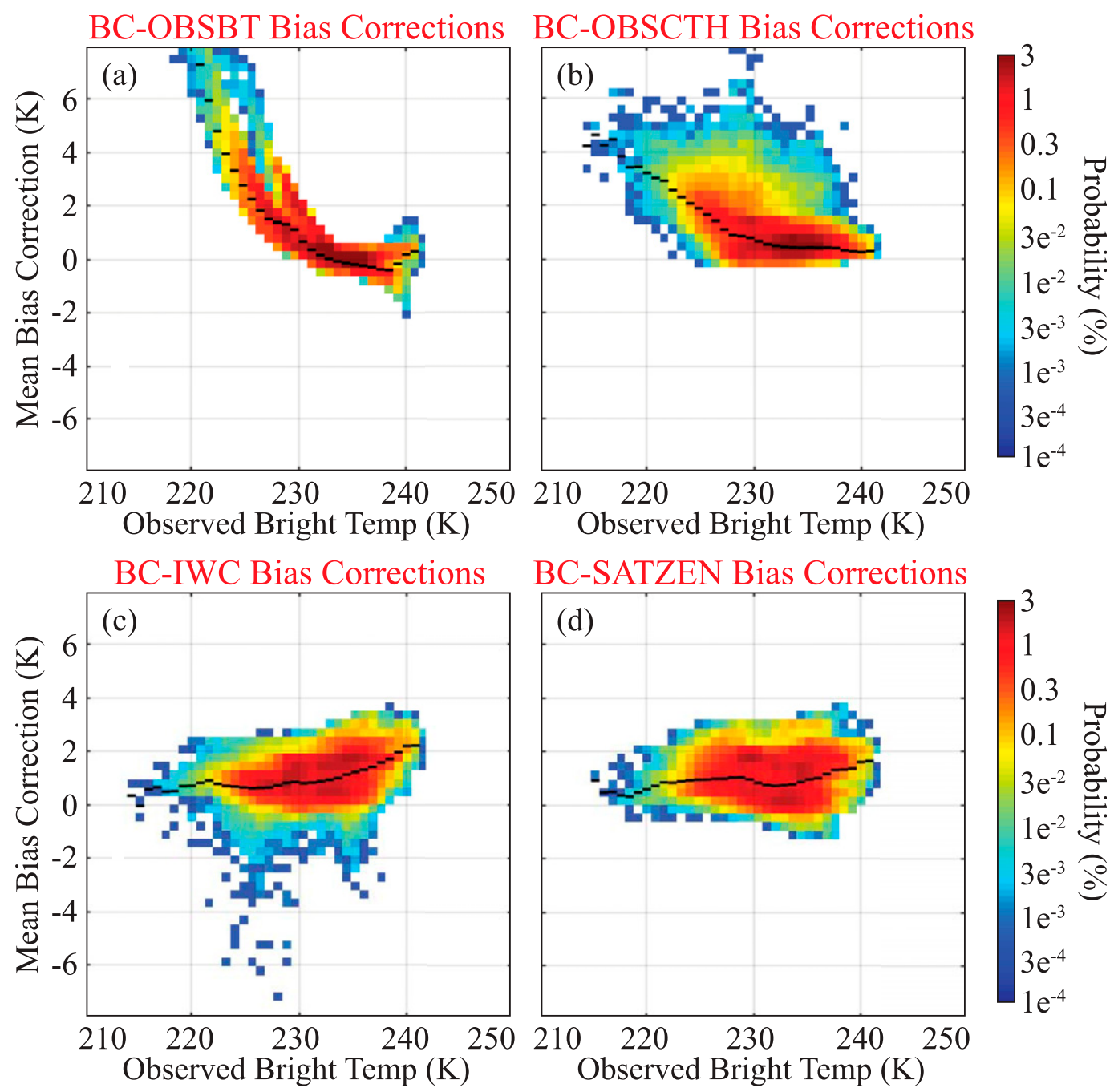

FIG. 7. Probability distribution of SEVIRI 6.2- $\mu \mathrm{m}$ ensemble mean brightness temperature corrections (K) from the (a) BC-OBSBT, (b) BC-OBSCTH, (c) BC-IWC, and (d) BC-SATZEN experiments plotted as a function of the observed 6.2- $\mu \mathrm{m}$ brightness temperatures. Data were accumulated at hourly intervals during a 72 -h period from 0100 UTC 28 May to 0000 UTC 31 May 2014. The horizontal black line segments represent the conditional bias in each column.

(Fig. 2a), which is good because that means that the OBSBT and OBSCTH predictors are able to account for the nonlinear, cloud-dependent conditional biases in that distribution. In contrast, the BC-IWC and BC-SATZEN experiments have much smaller BCs for the lowest brightness temperatures that then become larger for higher brightness temperatures. The mean $\mathrm{BC}$ is also larger during these experiments, which indicates that the IWC and SATZEN predictors did not have the same positive impact on the cloud field as the OBSBT and OBSCTH predictors. This behavior is consistent with the brightness temperature bias time series shown in Fig. 6a, and provides further evidence that it is necessary to use $\mathrm{BC}$ predictors sensitive to the $\mathrm{CTH}$ when assimilating all-sky infrared brightness temperatures.

\section{3) BRIGHTNESS TEMPERATURE INNOVATIONS}

Next, we examine the $6.2-\mu \mathrm{m}$ brightness temperature innovations during each experiment using the $2 \mathrm{D}$ probability distributions shown in Fig. 8. These distributions were constructed using the ensemble mean innovations accumulated at hourly intervals during the 72-h assimilation period. Inspection of Fig. 8a shows that the conditional mean innovations are close to zero across the entire distribution during the No-Assim experiment. This indicates that the conventional in situ observations by themselves do not have a systematic 
impact on the cloud and water vapor fields in the upper troposphere. During the No-BC experiment (Fig. 8b), the innovation pattern is very similar to the $\mathrm{OMB}$ departure distribution in the No-Assim experiment (Fig. 2a), with large (small) innovations occurring for lower (higher) brightness temperatures. This shows that the large conditional biases for the lower brightness temperatures are strongly corrected during this experiment, which is not surprising because $\mathrm{BC}$ was not applied to the brightness temperatures prior to their assimilation. A similar pattern emerges during the BC-IWC and BC-SATZEN experiments (Figs. 8e,f) because their smaller BCs for lower brightness temperatures (Figs. 7c,d) meant that large innovations were still possible during each assimilation cycle. In contrast, the mean innovations are very small across most of the distribution during the BC-OBSBT experiment (Fig. 8c) because the larger BCs for lower brightness temperatures (Fig. 7a) reduces the size of the resultant innovations. The distribution for the BC-OBSCTH experiment (Fig. 8d) has some larger negative innovations for the lower brightness temperatures, but is otherwise similar to the BC-OBSBT experiment. The smaller innovations during the BC-OBSBT and BC-OBSCTH experiments were likely beneficial because they limited potential imbalances in the model due to large analysis increments, while still leading to large reductions in the RMSE and bias (Figs. 6a,b).

\section{4) CONVENTIONAL OBSERVATION ERROR ANALYSIS}

Finally, we examine the impact of the infrared brightness temperatures and $\mathrm{BC}$ predictors on the accuracy of the prior ensemble mean analyses using OMB departure statistics accumulated during the 72-h assimilation period for the radiosonde temperature, relative humidity, and zonal and meridional wind observations. Figure 9 shows vertical profiles of RMSE for the No-Assim and No-BC experiments, along with percentage changes in RMSE for each BC experiment, whereas Fig. 10 shows the corresponding bias profiles. Summary statistics showing the percentage changes in RMSE and bias during each $\mathrm{BC}$ experiment relative to the No-Assim and No-BC experiments are shown in Tables 2 and 3, respectively.

Compared to the No-Assim experiment, the zonal and meridional wind speed errors in aggregate were slightly smaller during the BC-OBSBT and BC-OBSCTH experiments, but increased by $0.5 \%-0.8 \%$ during the BC-SATZEN and BC-IWC experiments (Table 2). Inspection of the zonal wind profiles (Figs. 9h,i) shows that the smaller RMSE during the BC-OBSBT and $\mathrm{BC}-\mathrm{OBSCTH}$ experiments were primarily due to larger improvements in the upper and lower troposphere, with some degradation evident in the midtroposphere. Both of these experiments also had the smallest meridional wind speed errors for most of the vertical layers (Figs. 9k,1). Indeed, the RMSE for the meridional wind speed observations was $1.4 \%$ and $0.8 \%$ smaller during the BC-OBSBT and BC-OBSCTH experiments, respectively, compared to a neutral impact when the IWC and SATZEN predictors were used (Table 3).

Assimilation of the infrared brightness temperatures led to very different impacts on the RMSE and bias for the radiosonde temperature observations. For example, though the RMSE in each experiment increased by $0.8 \%-1.0 \%$ relative to the No-Assim experiment, the bias was substantially reduced, with decreases ranging from $-1.7 \%$ during the No-BC experiment to $-6.1 \%$ for the BC-SATZEN experiment (Table 2). Overall, the smallest biases were obtained during the various $\mathrm{BC}$ experiments, with all but BC-SATZEN also having slightly smaller RMSEs than the No-BC experiment (Table 3). Comparison of the vertical profiles shows that the temperature RMSEs were smaller within most of the troposphere during the $\mathrm{BC}$ experiments (Fig. 9c); however, the presence of much larger errors near the tropopause led to only a neutral to slightly positive impact when all of the temperature observations are considered (Table 3).

For relative humidity, assimilating the infrared brightness temperatures without $\mathrm{BC}$ led to sharply higher bias $(30.1 \%)$ and RMSE $(0.8 \%)$ during the No-BC experiment (Table 2). In contrast, the overall RMSE and bias were much smaller during the various $\mathrm{BC}$ experiments regardless of which $\mathrm{BC}$ predictor was used (Table 3). Compared to the No-BC experiment, the largest RMSE reductions occurred during the BC-OBSCTH $(-1.8 \%)$ and BC-SATZEN $(-1.4 \%)$ experiments, with the largest bias reductions occurring during the BC-IWC $(-45.2 \%)$, BC-SATZEN $(-38.2 \%)$, and BC-OBSCTH $(-30.2 \%)$ experiments. The error profiles in Fig. 9f show that, though there are some differences between the $\mathrm{BC}$ experiments, that the RMSEs are smaller in most of the troposphere relative to the No-BC experiment. The biases are also greatly reduced in the middle and upper troposphere (Fig. 10b).

In summary, the results presented in this section show that assimilation of infrared brightness temperatures that are not bias-corrected leads to larger errors for all metrics, except for the temperature bias, relative to the No-Assim experiment. Removal of the brightness temperature biases prior to their assimilation, however, greatly improves the impact of the satellite observations, 

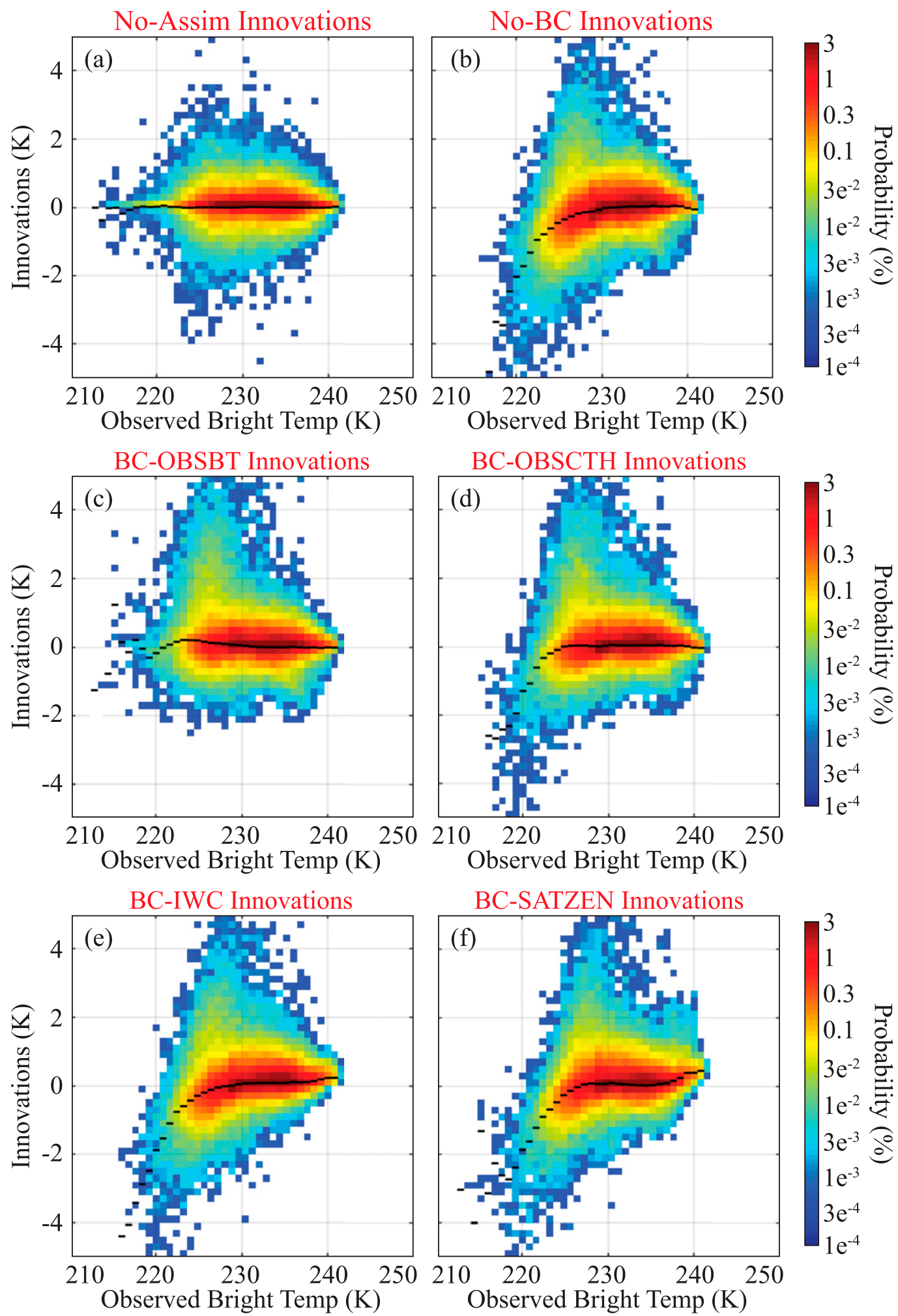

FIG. 8. Probability distributions of SEVIRI 6.2- $\mu \mathrm{m}$ brightness temperature innovations (K) for the (a) No-Assim, (b) No-BC, (c) BC-OBSBT, (d) BC-OBSCTH, (e) BC-IWC, and (f) BC-SATZEN experiments plotted as a function of the observed $6.2-\mu \mathrm{m}$ brightness temperatures $(\mathrm{K})$. Data were accumulated at hourly intervals from 0000 UTC 28 May to 0000 UTC 31 May 2014. The black line segments depict the mean innovation in each column. 

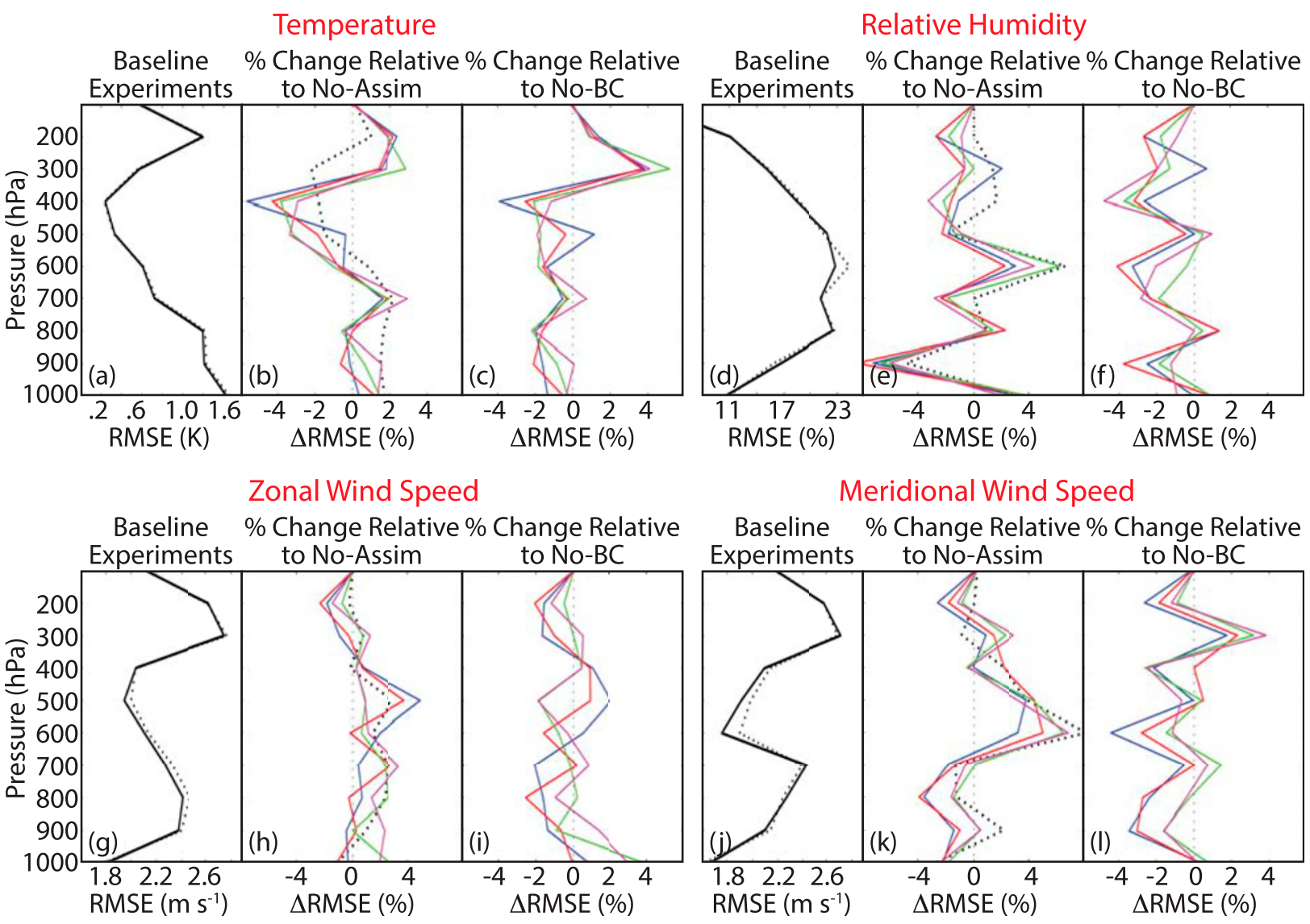

FIG. 9. (a) Vertical profiles of temperature root-mean-square error (RMSE; K) from the No-Assim (solid black) and No-BC experiments (dashed black), with percentage changes in RMSE for the BC-OBSBT (blue), BC-OBSCTH (red), BC-IWC (green), and BC-SATZEN (magenta) experiments relative to the (b) No-Assim and (c) No-BC experiments. (d)-(f) As in (a)-(c), but for showing vertical profiles of relative humidity RMSE (\%). (g)-(i) As in (a)-(c), but for showing vertical profiles of zonal wind speed RMSE (m s ${ }^{-1}$ ). (j)-(1) As in (a)-(c), but for showing vertical profiles of meridional wind speed RMSE $\left(\mathrm{m} \mathrm{s}^{-1}\right)$. The error profiles were computed using data from the ensemble mean prior analyses at hourly intervals over a 3-day period from 0000 UTC 28 May to 0000 UTC 31 May 2014.

with the largest percentage decreases in the errors realized for the relative humidity observations. Overall, the OBSCTH and OBSBT predictors were the most useful because not only did their use lead to more accurate cloud and water vapor fields, but they also produced the smallest RMSEs for the wind and temperature fields.

\section{c. Symmetric bias correction predictors}

In this section, we assess the impact of using "symmetric" predictors to remove the bias from allsky infrared brightness temperatures. As discussed in the introduction, symmetric predictors that represent the average of an observed quantity and its corresponding model equivalent have been extensively used when developing all-sky observation error models. First introduced by Geer and Bauer (2011), symmetric predictors have been shown in various studies to lead to more Gaussian OMB departure statistics when a suitable cloud impact parameter is used to dynamically assign the error variance to each observation. This symmetric observation error approach is now widely used in operational DA systems that assimilate all-sky microwave radiances because it leads to more accurate forecasts through better utilization of the satellite observations.

Despite their widespread use in all-sky observation error models, it is not clear if symmetric variables can also serve as effective bias predictors, especially in the presence of complex nonlinear bias patterns. To explore their potential utility, two additional sets of experiments were run where the $\mathrm{CTH}$ or the $6.2-\mu \mathrm{m}$ brightness temperatures were used as the bias predictor. These variables were chosen because they are either a direct measure of, or are sensitive to, the cloud height, which is an excellent measure of cloud impact in all-sky infrared brightness temperatures. Experiments were performed where observed (BC-OBSBT, BC-OBSCTH), simulated 

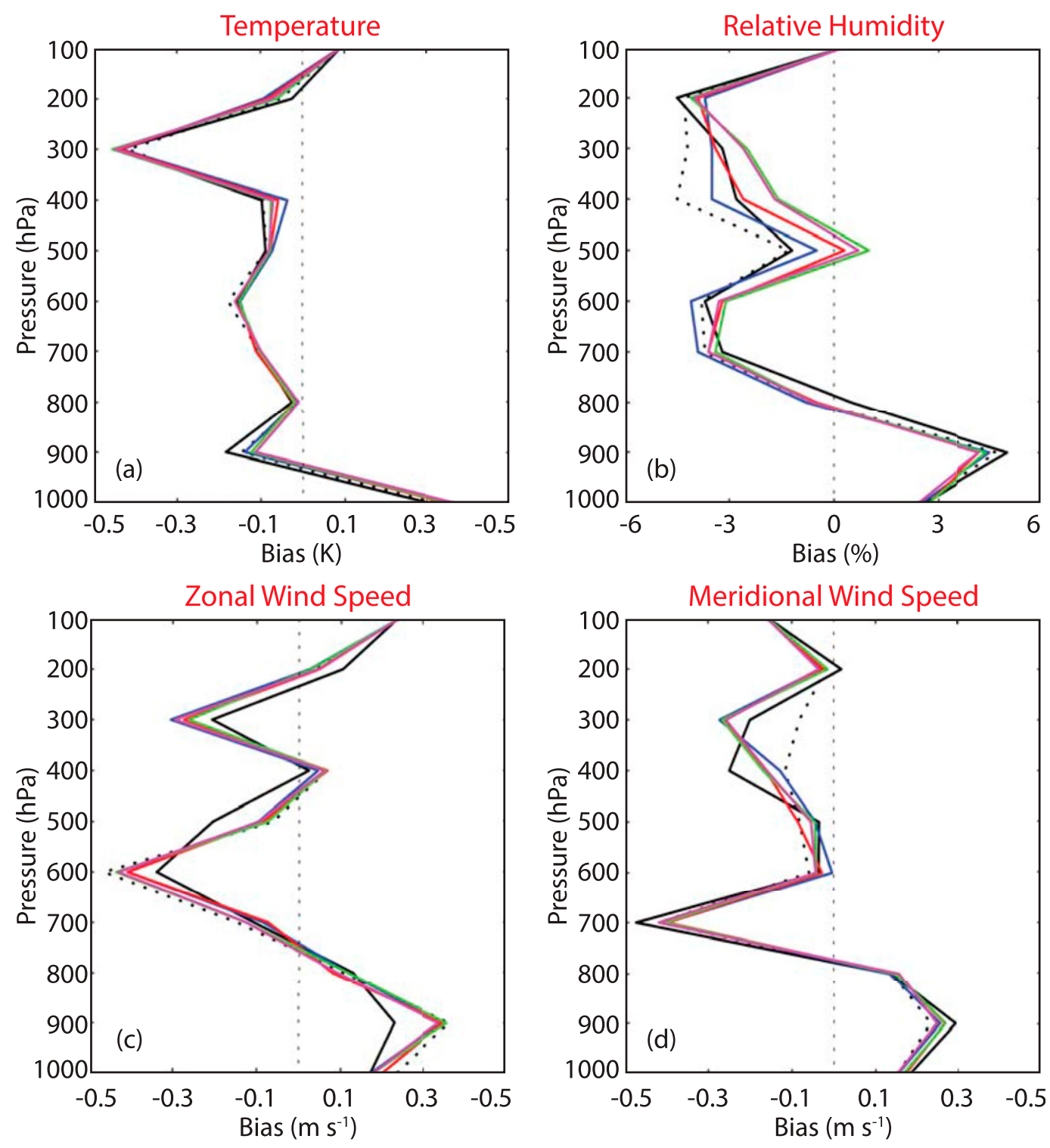

FIG. 10. Vertical profiles of (a) temperature bias (K), (b) relative humidity bias (\%), (c) zonal wind speed bias $\left(\mathrm{m} \mathrm{s}^{-1}\right)$, and (d) meridional wind speed bias $\left(\mathrm{m} \mathrm{s}^{-1}\right)$ for the No-Assim (solid black), No-BC (dashed black), BC-OBSBT (blue), BC-OBSCTH (red), BC-IWC (green), and BC-SATZEN (magenta) experiments. The error profiles were computed using data from the prior analyses over a 3-day period from 0100 UTC 28 May to 0000 UTC 31 May 2014.

(BC-SIMBT, BC-SIMCTH), or symmetric (BC-SYMBT, $\mathrm{BC}-\mathrm{SYMCTH})$ quantities for each $\mathrm{BC}$ predictor variable were used to remove the bias from the infrared brightness temperatures prior to their assimilation. For the simulated CTH predictor, the cloud top was identified as the first model level looking downward from the model top in which the vertically integrated cloud hydrometeor mixing ratio was $>10^{-4} \mathrm{~kg} \mathrm{~kg}^{-1}$. All of the cloud hydrometeor species predicted by the microphysics parameterization scheme were used when computing this quantity. The modeled land/ocean surface elevation was used as the predictor value when the accumulated cloud mixing ratio threshold was not surpassed. The same approach was used for the observed CTH retrievals where grid points identified as clear were also set to the model surface elevation.

Summary statistics showing the percentage changes relative to the No-BC experiment for the radiosonde temperature, relative humidity, and zonal and meridional wind speed observations are shown in Tables 4 and 5, respectively, for experiments using the various $6.2-\mu \mathrm{m}$ brightness temperature or $\mathrm{CTH}$ quantities as the bias 
TABLE 2. Percentage changes in root-mean-square error (RMSE) and bias for the zonal and meridional wind speed, temperature, and relative humidity for the BC-OBSBT, BC-OBSCTH, BC-IWC, and BC-SATZEN experiments relative to the No-Assim experiment. The statistics were computed using all of the radiosonde observations and output from the prior ensemble mean analyses during the 72-h assimilation period.

\begin{tabular}{|c|c|c|c|c|c|c|}
\hline \multirow[b]{2}{*}{ Experiment } & \multirow{2}{*}{$\frac{U}{\mathrm{RMSE}}$} & \multirow{2}{*}{$\frac{V}{\mathrm{RMSE}}$} & \multicolumn{2}{|c|}{$T$} & \multicolumn{2}{|c|}{$\mathrm{RH}$} \\
\hline & & & RMSE & BIAS & RMSE & BIAS \\
\hline No-BC-No-Assim & $0.9 \%$ & $0.6 \%$ & $1.0 \%$ & $-1.7 \%$ & $0.8 \%$ & $30.1 \%$ \\
\hline BC-OBSBT-No-Assim & $0.0 \%$ & $-0.8 \%$ & $0.8 \%$ & $-4.7 \%$ & $-0.4 \%$ & $9.8 \%$ \\
\hline BC-OBSCTH-No-Assim & $-0.1 \%$ & $-0.2 \%$ & $0.8 \%$ & $-3.0 \%$ & $-1.0 \%$ & $-9.2 \%$ \\
\hline BC-IWC-No-Assim & $0.7 \%$ & $0.6 \%$ & $0.9 \%$ & $-4.8 \%$ & $-0.1 \%$ & $-28.8 \%$ \\
\hline BC-SATZEN-No-Assim & $0.8 \%$ & $0.5 \%$ & $1.0 \%$ & $-6.1 \%$ & $-0.6 \%$ & $-19.6 \%$ \\
\hline
\end{tabular}

predictor. These statistics were computed using output from the prior ensemble mean analyses. Overall, the results show that using symmetric bias predictors does not lead to a more accurate model background. For experiments using the $6.2-\mu \mathrm{m}$ brightness temperature predictors (Table 4), the error reduction for each radiosonde observation type is smaller during the BC-SYMBT experiment than it is during the BC-OBSBT experiment. Likewise, when the CTH quantities are used as the bias predictors (Table 5), the most accurate analyses are obtained when the observed quantity is used during the BC-OBSCTH experiment. The error reductions during the BC-SYMCTH experiment are either in between those obtained during the BC-OBSCTH and BC-SIMCTH experiments, or are smaller than both of them. A possible reason for the relatively poor performance during both of the symmetric bias predictor experiments is that, with the exception of relative humidity, the error reductions are consistently smaller when the simulated predictors are used to remove the bias from the all-sky infrared observations. Thus, inclusion of the model-simulated predictor value when computing the symmetric bias predictor is not beneficial. Instead, it is more effective to simply use the observed quantity as the bias predictor.

To examine this behavior more closely, Fig. 11 shows 2D probability distributions for the ensemble mean $6.2-\mu \mathrm{m}$ brightness temperature $\mathrm{BCs}$ and innovations when the simulated, observed, and symmetric CTH bias predictors are used. Similar results are obtained for experiments employing the $6.2-\mu \mathrm{m}$ brightness temperature predictors (not shown). Comparison of the BC distributions reveals a relatively flat pattern during the BC-SIMCTH experiment (Fig. 11a), which shows that the model-derived $\mathrm{CTH}$ predictor is unable to account for the large negative conditional biases for brightness temperatures $<230 \mathrm{~K}$ (Fig. 2a). The smaller BCs for the lower brightness temperatures during this experiment stand in sharp contrast to the much larger BCs during the BC-OBSCTH experiment (Fig. 11e). Because the symmetric predictor is simply the mean of the observed and simulated quantities, the $\mathrm{BC}$ distribution during the BC-SYMCTH experiment (Fig. 11c) is a hybrid of the BC-OBSCTH and BC-SIMCTH distributions. As such, the smaller BCs for the lower brightness temperatures due to the impact of the model-simulated quantity leads to larger innovations than occurred during the BC-OBSCTH experiment (Figs. 11d,f). As was shown in the previous section, experiments containing larger innovations for the lower brightness temperatures associated with optically thick upper-level clouds were generally less accurate when assessed using radiosonde observations. This result suggests that, though symmetric predictors have been shown to improve the performance of all-sky observation error models, they may not work as well for all-sky BC. Further studies using other

TABLE 3. Percentage changes in root-mean-square error (RMSE) and bias for the zonal and meridional wind speed, temperature, and relative humidity for the BC-OBSBT, BC-OBSCTH, BC-IWC, and BC-SATZEN experiments relative to the No-BC experiment. The statistics were computed using all of the radiosonde observations and output from the prior ensemble mean analyses during the 72-h assimilation period.

\begin{tabular}{|c|c|c|c|c|c|c|}
\hline \multirow[b]{2}{*}{ Experiment } & \multirow{2}{*}{$\frac{U}{\mathrm{RMSE}}$} & \multirow{2}{*}{$\frac{V}{\mathrm{RMSE}}$} & \multicolumn{2}{|c|}{$T$} & \multicolumn{2}{|c|}{$\mathrm{RH}$} \\
\hline & & & RMSE & BIAS & RMSE & BIAS \\
\hline BC-OBSBT-No-BC & $-0.9 \%$ & $-1.4 \%$ & $-0.2 \%$ & $-3.1 \%$ & $-1.2 \%$ & $-15.6 \%$ \\
\hline BC-OBSCTH-No-BC & $-1.0 \%$ & $-0.8 \%$ & $-0.2 \%$ & $-1.3 \%$ & $-1.8 \%$ & $-30.2 \%$ \\
\hline BC-IWC-No-BC & $-0.2 \%$ & $0.0 \%$ & $-0.1 \%$ & $-3.2 \%$ & $-0.9 \%$ & $-45.2 \%$ \\
\hline BC-SATZEN-No-BC & $-0.1 \%$ & $-0.1 \%$ & $0.1 \%$ & $-4.5 \%$ & $-1.4 \%$ & $-38.2 \%$ \\
\hline
\end{tabular}


TABLE 4. Percentage changes in root-mean-square error (RMSE) and bias for the zonal and meridional wind speed, temperature, and relative humidity for the BC-OBSBT, BC-SYMBT, and BC-SIMBT experiments relative to the No-BC experiment. The statistics were computed using all of the radiosonde observations and output from the prior ensemble mean analyses during the 72-h assimilation period.

\begin{tabular}{|c|c|c|c|c|c|c|}
\hline \multirow[b]{2}{*}{ Experiment } & \multirow{2}{*}{$\frac{U}{\mathrm{RMSE}}$} & \multirow{2}{*}{$\frac{V}{\text { RMSE }}$} & \multicolumn{2}{|c|}{$T$} & \multicolumn{2}{|c|}{$\mathrm{RH}$} \\
\hline & & & RMSE & BIAS & RMSE & BIAS \\
\hline BC-OBSBT-No-BC & $-0.9 \%$ & $-1.4 \%$ & $-0.2 \%$ & $-3.1 \%$ & $-1.2 \%$ & $-15.6 \%$ \\
\hline BC-SYMBT-No-BC & $-0.1 \%$ & $0.0 \%$ & $-0.1 \%$ & $-2.0 \%$ & $-1.0 \%$ & $-29.6 \%$ \\
\hline BC-SIMBT-No-BC & $1.0 \%$ & $1.3 \%$ & $0.6 \%$ & $-1.1 \%$ & $-0.8 \%$ & $-55.8 \%$ \\
\hline
\end{tabular}

satellite bands and models are necessary to explore this in more detail.

\section{Discussion and conclusions}

In this study, ensemble DA experiments were performed using the regional-scale KENDA system to evaluate the ability of all-sky infrared brightness temperatures to improve the accuracy of the ensemble prior analyses used during each assimilation cycle. Observations from the $6.2-\mu \mathrm{m}$ band on the SEVIRI sensor were assimilated at hourly intervals over a 3-day period in May 2014. This infrared band is primarily sensitive to clouds and water vapor in the upper troposphere. Various experiments were performed in which different $\mathrm{BC}$ predictors were used to remove biases from the all-sky brightness temperatures prior to their assimilation. Results from these $\mathrm{BC}$ experiments were compared to baseline experiments in which the brightness temperatures were either not assimilated (No-Assim) or were assimilated without first removing their biases (No-BC). This study builds upon the passive monitoring experiments described in Otkin et al. (2018) by exploring the impact of linear and nonlinear BC predictors during experiments in which all-sky infrared brightness temperatures are actively assimilated.

Overall, inspection of the $6.2-\mu \mathrm{m}$ brightness temperature OMB departure distribution from the No-Assim experiment revealed that the conditional biases exhibited a nonlinear pattern characterized by small biases for higher brightness temperatures and increasingly large negative biases for lower brightness temperatures.
Though the negative conditional biases are likely at least partially due to inaccuracies in the forward observation operator, they also indicate that the model analyses do not contain enough cloud condensate in the upper troposphere. This deficiency, whether due to insufficient spatial coverage or cloud optical depth, represents a systematic bias in the NWP model depiction of the cloud field. Thus, trying to add these upper-level clouds during an assimilation cycle could be problematic because of aliasing of the cloud information onto other model variables and the tendency for the model to revert back to its preferred state during the subsequent forecast period.

Evaluation of the No-BC experiment showed that assimilation of the infrared brightness temperatures without first removing their biases almost always degraded the accuracy of the ensemble prior analyses based on larger OMB departures for the radiosonde observations. In particular, the summary statistics showed that the relative humidity bias and RMSE were much larger during this experiment than they were during the No-Assim experiment. Despite having strong sensitivity to water vapor in the upper troposphere, assimilating infrared brightness temperatures without BC actually increased the relative humidity RMSE, primarily because of a large increase in the moist bias already present in the No-Assim experiment. The No-BC experiment was also characterized by smaller $6.2-\mu \mathrm{m}$ brightness temperature OMB departures, which suggests that instead of adding clouds to the analysis, the DA system instead added more water vapor. An alternative explanation is that a portion of the cloud

TABLE 5. Percentage changes in root-mean-square error (RMSE) and bias for the zonal and meridional wind speed, temperature, and relative humidity for the BC-OBSCTH, BC-SYMCTH, and BC-SIMCTH experiments relative to the No-BC experiment. The statistics were computed using all of the radiosonde observations and output from the prior ensemble mean analyses during the 72-h assimilation period.

\begin{tabular}{|c|c|c|c|c|c|c|}
\hline \multirow[b]{2}{*}{ Experiment } & \multirow{2}{*}{$\frac{U}{\mathrm{RMSE}}$} & \multirow{2}{*}{$\frac{V}{\mathrm{RMSE}}$} & \multicolumn{2}{|c|}{$T$} & \multicolumn{2}{|c|}{ RH } \\
\hline & & & RMSE & BIAS & RMSE & BIAS \\
\hline BC-OBSCTH-No-BC & $-1.0 \%$ & $-0.8 \%$ & $-0.2 \%$ & $-1.3 \%$ & $-1.8 \%$ & $-30.2 \%$ \\
\hline BC-SYMCTH-No-BC & $-0.4 \%$ & $-0.5 \%$ & $0.0 \%$ & $-3.1 \%$ & $-1.2 \%$ & $-27.1 \%$ \\
\hline BC-SIMCTH-No-BC & $-0.2 \%$ & $0.5 \%$ & $0.0 \%$ & $-1.2 \%$ & $-1.5 \%$ & $-43.2 \%$ \\
\hline
\end{tabular}



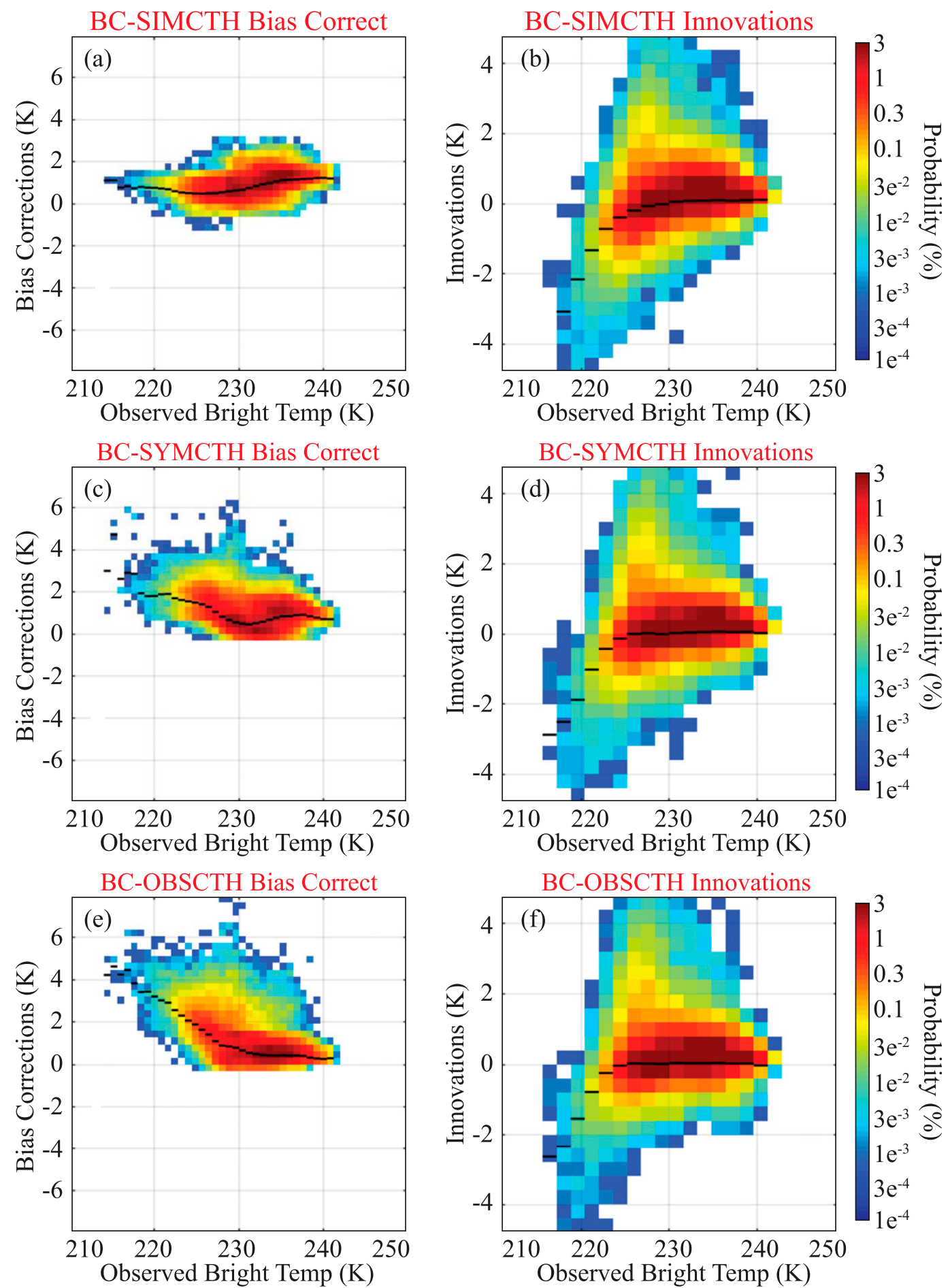

FIG. 11. Probability distributions for the SEVIRI $6.2-\mu \mathrm{m}$ brightness temperature (a) bias corrections and (b) innovations from the BC-SIMCTH experiment plotted as a function of the observed $6.2-\mu \mathrm{m}$ brightness temperatures (K). (c),(d) As in (a),(b), but for the BC-SYMCTH experiment. (e),(f) As in (a),(b), but for the BC-OBSCTH experiment. Data were accumulated at hourly intervals from 0000 UTC 28 May to 0000 UTC 31 May 2014. The black line segments depict the mean bias correction or innovation in each column. 
condensate added to the ensemble posterior analyses during a given assimilation cycle evaporated during the subsequent model integration period, thereby increasing the moist bias. Regardless, this result suggests that the analyses were being too strongly constrained by the all-sky infrared brightness temperatures during the No-BC experiment in situations where the model was unable to properly handle the additional cloud information.

The subsequent removal of linear and nonlinear conditional biases from the all-sky brightness temperatures through use of a third-order polynomial expansion of the OMB departures and various BC predictors led to smaller errors for all of the radiosonde observation types when compared to the No-BC experiment. The largest improvements occurred for the relative humidity observations where the moist bias in the upper troposphere was greatly reduced. Notable improvements also occurred in the temperature bias and in the RMSE for the zonal and meridional wind speed components during the BC-OBSBT and BC-OBSCTH experiments. The temperature RMSE was also smaller in most of the troposphere; however, a spike of larger errors near and above the tropopause led to a neutral impact when all temperature observations were considered.

Comparison of the various predictors showed that those sensitive to the location of the cloud top had the largest positive impact on the model background based on improved fits to the radiosonde observations. The observed CTH and observed $6.2-\mu \mathrm{m}$ brightness temperature predictors were the best overall because their use not only led to the smallest relative humidity errors, but also led to the largest error reductions for the zonal and meridional wind speed observations and the smallest degradation for the temperature RMSE. Both of these predictors also improved the cloud field much more than the other predictors, as signified by the smaller brightness temperature RMSE and bias. The larger improvements during the BC-OBSBT and BC-OBSCTH experiments were primarily due to the ability of the cloud-sensitive predictors to more effectively remove the large negative biases from brightness temperatures $<230 \mathrm{~K}$. The larger BCs for these clouds then led to smaller brightness temperature innovations and presumably fewer model spinup problems during the subsequent 1-h forecasts. Additional experiments using the OBSCTH predictor revealed that it was beneficial to use higher-order nonlinear BC terms to remove the bias from the all-sky infrared brightness temperatures. For example, the radiosonde OMB departure errors generally decreased as the order of the polynomial expansion increased from the zeroth order to the third order. Finally, an additional set of experiments showed that symmetric bias predictors do not improve the model analyses as effectively as the observed predictors do by themselves. This suggests that, though symmetric predictors have proven utility for all-sky observation error models, they may not be as useful when developing all-sky BC methods.

This study has shown that assimilation of all-sky infrared brightness temperatures substantially improves the accuracy of the cloud and water vapor fields in the prior ensemble analyses when cloud-sensitive predictors and higher-order $\mathrm{BC}$ terms are used to remove linear and nonlinear conditional biases from the observations prior to their assimilation. Though encouraging, additional studies are necessary to evaluate the ability of the NBC method and the all-sky infrared brightness temperatures to improve the accuracy of the model analyses during other seasons containing different cloud regimes potentially characterized by different conditional bias patterns. It will also be necessary to perform ensemble forecasts to evaluate how long the improved cloud and water vapor fields persist during the forecast period. Data assimilation experiments should also be performed for the SEVIRI 7.3- $\mu \mathrm{m}$ band that is sensitive to clouds and water vapor in the middle and upper troposphere, as well as for atmospheric window bands that are sensitive to clouds and surface properties. Such experiments performed over longer time periods (e.g., a month or longer) would promote a more thorough assessment of the performance of the NBC method.

It is important to note that the experiments performed during this study are only an initial step toward inclusion of the all-sky infrared observations in the KENDA system and that additional developments have the potential to substantially increase their impact. For example, there is great promise in pairing the NBC method to a dynamic all-sky observation error model because that could lead to more effective use of the clear- and cloudy-sky brightness temperatures. It would also be helpful to explore the benefits of more frequent assimilation updates and in assimilating brightness temperatures from more than one infrared band, though that would require development of a correlated observation error model. The results also suggest that some attention should be given to developing methods that can increase the ensemble spread in the cloud hydrometeor variables. These topics are all left to future work.

Acknowledgments. We gratefully acknowledge Jesse Stroik from the University of Wisconsin-Madison and Hendrik Reich, Andreas Rhodin, Robin Faulwetter, and Axel Hutt from the German DWD for their assistance porting and installing the KENDA system and basic cycling (BACY) scripts to the NOAA/NESDIS/STAR "S4" 
supercomputer located at the University of WisconsinMadison. The S4 supercomputer (Boukabara et al. 2016) was used to perform all of the cycled DA experiments. The lead author was partially supported by a University of Reading International Research Studentship.

\section{REFERENCES}

Aksoy, A., D. C. Dowell, and C. Snyder, 2009: A multicase comparative assessment of the ensemble Kalman filter for assimilation of radar observations. Part I: Storm-scale analysis. Mon. Wea. Rev., 137, 1805-1824, https://doi.org/10.1175/ 2008MWR2691.1.

Anderson, J., and S. Anderson, 1999: A Monte Carlo implementation of the nonlinear filtering problem to produce ensemble assimilations and forecasts. Mon. Wea. Rev., 127, 2741-2758, https://doi.org/10.1175/1520-0493(1999)127<2741: AMCIOT $>2.0 . \mathrm{CO} ; 2$.

Aonashi, K., and H. Eito, 2011: Displaced ensemble variations assimilation method to incorporate microwave imager brightness temperatures into a cloud resolving model. J. Meteor. Soc. Japan, 89, 175-194, https://doi.org/10.2151/ jmsj.2011-301.

Aravequia, J. A., I. Szunyogh, E. J. Fertig, E. Kalnay, D. Kuhl, and E. J. Kostelich, 2011: Evaluation of a strategy for the assimilation of satellite radiance observations with the local ensemble transform Kalman filter. Mon. Wea. Rev., 139, 1932-1951, https://doi.org/10.1175/2010MWR3515.1.

Auligne, T., A. P. McNally, and D. P. Dee, 2007: Adaptive bias correction for satellite data in a numerical weather prediction system. Quart. J. Roy. Meteor. Soc., 133, 631-642, https://doi.org/10.1002/qj.56.

Baldauf, M., A. Seifert, J. Forstner, D. Majewski, M. Raschendorfer, and T. Reinhardt, 2011: Operational convective-scale numerica weather prediction with the COSMO Model: Description and sensitivities. Mon. Wea. Rev., 139, 3887-3905, https://doi.org/ 10.1175/MWR-D-10-05013.1.

Baordo, F., and A. J. Geer, 2016: Assimilation of SSMIS humiditysounding channels in all-sky conditions over land using a dynamic emissivity retrieval. Quart. J. Roy. Meteor. Soc., 142, 2854-2866, https://doi.org/10.1002/qj.2873.

Bauer, P., A. J. Geer, P. Lopez, and D. Salmond, 2010: Direct 4DVar assimilation of all-sky radiances: Part I. Implementation. Quart. J. Roy. Meteor. Soc., 136, 1868-1885, https://doi.org/ 10.1002/qj.659.

— , and Coauthors, 2011: Satellite cloud and precipitation assimilation at operational NWP centres. Quart. J. Roy. Meteor. Soc., 137, 1934-1951, https://doi.org/10.1002/qj.905.

Baum, B. A., P. Yang, A. J. Heymsfield, A. Bansemer, A. Merrelli, C. Schmitt, and C. Wang, 2014: Ice cloud bulk single-scattering property models with the full phase matrix at wavelength from 0.2 to $100 \mu \mathrm{m}$. J. Quant. Spectrosc. Radiat. Transfer, 146, 123-139, https://doi.org/10.1016/j.jqsrt.2014.02.029.

Bengtsson, L., and K. Hodges, 2005: On the impact of humidity observations in numerical weather prediction. Tellus, 57A 701-708, https://doi.org/10.1111/j.1600-0870.2005.00142.x.

Berner, J., and Coauthors, 2017: Stochastic parameterization: Toward a new view of weather and climate models. Bull. Amer. Meteor. Soc., 98, 565-588, https://doi.org/10.1175/ BAMS-D-15-00268.1.
Bessho, K., and Coauthors, 2016: An introduction to Himawari-8/9Japan's new-generation geostationary meteorological satellites. J. Meteor. Soc. Japan, 94, 151-183, https://doi.org/10.2151/ jmsj.2016-009.

Bocquet, M., C. A. Pires, and L. Wu, 2010: Beyond Gaussian statistical modelling in geophysical data assimilation. Mon. Wea. Rev., 138, 2997-3023, https://doi.org/10.1175/ 2010MWR3164.1.

Bormann, N., A. J. Geer, and P. Bauer, 2011: Estimates of observation-error characteristics in clear and cloudy regions for microwave imager radiances from NWP. Quart. J. Roy. Meteor. Soc., 137, 2014-2023, https://doi.org/10.1002/qj.833. M. Bonavita, R. Dragani, R. Eresmaa, M. Matricardi, and A. McNally, 2016: Enhancing the impact of IASI observations through an updated observation-error covariance matrix. Quart. J. Roy. Meteor. Soc., 142, 1767-178, https://doi.org/ 10.1002/qj.2774.

Boukabara, S. A., and Coauthors, 2016: S4: An O2R/R2O infrastructure for optimizing satellite data utilization in NOAA numerical modeling systems: A step toward bridging the gap between research and operations. Bull. Amer. Meteor. Soc., 97, 2359-2378, https://doi.org/10.1175/BAMS-D-14-00188.1.

Campbell, W. F., E. A. Satterfield, B. Ruston, and N. L. Baker, 2017: Accounting for correlated observation error in a dual-formulation 4D variational data assimilation system. Mon. Wea. Rev., 145, 1019-1032, https://doi.org/10.1175/ MWR-D-16-0240.1.

Cintineo, R., J. A. Otkin, M. Xue, and F. Kong, 2014: Evaluating the performance of planetary boundary layer and cloud microphysical parameterization schemes in convection permitting ensemble forecasts using synthetic GOES-13 satellite observations. Mon. Wea. Rev., 142, 163-182, https://doi.org/ 10.1175/MWR-D-13-00143.1.

$\longrightarrow,-$ T. Jones, S. Koch, and D. J. Stensrud, 2016: Assimilation of synthetic GOES-R ABI infrared brightness temperatures and WSR-88D radar observations in a high-resolution OSSE. Mon. Wea. Rev., 144, 3159-3180, https://doi.org/ 10.1175/MWR-D-15-0366.1.

Dee, D. P., 2005: Bias and data assimilation. Quart. J. Roy. Meteor. Soc., 131, 3323-3343, https://doi.org/10.1256/qj.05.137.

, and S. Uppala, 2009: Variational bias correction of satellite radiance data in the ERA-Interim reanalysis. Quart. J. Roy. Meteor. Soc., 135, 1830-1841, https://doi.org/10.1002/qj.493.

Derber, J. C., and W.-S. Wu, 1998: The use of TOVS cloudcleared radiances in the NCEP SSI analysis system. Mon. Wea. Rev., 126, 2287-2299, https://doi.org/10.1175/15200493(1998)126<2287:TUOTCC >2.0.CO;2.

— D. F. Parrish, and S. J. Lord, 1991: The new global operational analysis system at the National Meteorological Center. Wea. Forecasting, 6, 538-547, https://doi.org/10.1175/ 1520-0434(1991)006<0538:TNGOAS > 2.0.CO;2.

Derrien, M., and H. Le Gleau, 2005: MSG/SEVIRI cloud mask and type from SAF NWC. Int. J. Remote Sens., 26, 4707-4732, https://doi.org/10.1080/01431160500166128.

Dowell, D. C., F. Zhang, L. Wicker, C. Snyder, and N. A. Crook, 2004: Wind and temperature retrievals in the 17 May 1981 Arcadia, Oklahoma, supercell: Ensemble Kalman filter experiments. Mon. Wea. Rev., 132, 1982-2005, https://doi.org/ 10.1175/1520-0493(2004)132<1982:WATRIT>2.0.CO;2.

Eikenberg, S., C. Kohler, A. Siefert, and S. Crewell, 2015: How microphysical choices affect simulated infrared brightness temperatures. Atmos. Res., 156, 67-79, https://doi.org/10.1016/ j.atmosres.2014.12.010 
Errico, R. M., P. Bauer, and J.-F. Mahfouf, 2007: Issues regarding the assimilation of cloud and precipitation data. J. Atmos. Sci., 64, 3785-3798, https://doi.org/10.1175/2006JAS2044.1.

Eyre, J. R., 1992: A bias correction scheme for simulated TOVS brightness temperatures. Tech. Memo. 186, ECMWF, Reading, United Kingdom, 34 pp., https://www.ecmwf.int/en/ elibrary/9330-bias-correction-scheme-simulated-tovs-brightnesstemperatures.

_ 2016: Observation bias correction schemes in data assimilation systems: A theoretical study of some of their properties. Quart. J. Roy. Meteor. Soc., 142, 2284-2291, https://doi.org/ 10.1002/qj.2819.

Fabry, F., and J. Sun, 2010: For how long should what data be assimilated for the mesoscale forecasting of convection and why? Part I: On the propagation of initial condition errors and their implications for data assimilation. Mon. Wea. Rev., 138, 242-255, https://doi.org/10.1175/2009MWR2883.1.

Fertig, E. J., and Coauthors, 2009: Observation bias correction with an ensemble Kalman filter. Tellus, 61A, 210-226, https:// doi.org/10.1111/j.1600-0870.2008.00378.x.

Geer, A. J., and P. Bauer, 2011: Observation errors in all-sky data assimilation. Quart. J. Roy. Meteor. Soc., 137, 2024-2037, https://doi.org/10.1002/qj.830.

,-- , and S. J. English, 2012: Assimilating AMSU-A temperature sounding channels in the presence of cloud and precipitation. Tech. Memo. 670, ECMWF, Reading, United Kingdom, 43 pp., https://www.ecmwf.int/sites/default/files/ elibrary/2012/9514-assimilating-amsu-temperature-soundingchannels-presence-cloud-and-precipitation.pdf.

—_, F. Baordo, N. Bormann, and S. English, 2014: All-sky assimilation of microwave humidity sounders. Tech. Memo. 741, ECMWF, Reading, United Kingdom, 59 pp., https:// www.ecmwf.int/sites/default/files/elibrary/2014/9507-all-skyassimilation-microwave-humidity-sounders.pdf.

—_ and Coauthors, 2017: The growing impact of satellite observations sensitive to humidity, cloud and precipitation. Quart. J. Roy. Meteor. Soc., 143, 3189-3206, https://doi.org/10.1002/ qj.3172.

_- and Coauthors, 2018: All-sky satellite data assimilation at operational weather forecasting centres. Quart. J. Roy. Meteor. Soc., 144, 1191-1217, https://doi.org/10.1002/qj.3202.

_ S. Migliorini, and M. Matricardi, 2019: All-sky assimilation of infrared radiances sensitive to mid- and upper-tropospheric moisture and cloud. Atmos. Meas. Tech., 12, 4903-4929, https://doi.org/10.5194/amt-12-4903-2019.

Guidard, V., N. Fourrie, P. Brousseau, and F. Rabier, 2011: Impact of IASI assimilation at global and convective scales and challenges for the assimilation of cloudy scenes. Quart. J. Roy. Meteor. Soc., 137, 1975-1987, https://doi.org/10.1002/qj.928.

Gustafsson, N., and Coauthors, 2018: Survey of data assimilation methods for convective-scale numerical weather prediction at operational centres. Quart. J. Roy. Meteor. Soc., 144, 12181256, https://doi.org/10.1002/qj.3179.

Harnisch, F., M. Weissmann, and A. Perianez, 2016: Error model for the assimilation of cloud-affected infrared satellite observations in an ensemble data assimilation system. Quart. J. Roy. Meteor. Soc., 142, 1797-1808, https://doi.org/10.1002/ qj. 2776 .

Harris, B. A., and G. Kelly, 2001: A satellite radiance-bias correction scheme for data assimilation. Quart. J. Roy. Meteor. Soc., 127, 1453-1468, https://doi.org/10.1002/qj.49712757418.

Heilliette, S., and L. Garand, 2007: A practical approach for the assimilation of cloudy infrared radiances and its evaluation using AIRS simulated observations. Atmos.-Ocean, 45, 211225, https://doi.org/10.3137/ao.450403.

Hilton, F., N. C. Atkinson, S. J. English, and J. R. Eyre, 2009: Assimilation of IASI at the Met Office and assessment of its impact through observing system experiments. Quart. J. Roy. Meteor. Soc., 135, 495-505, https://doi.org/10.1002/ qj.379.

Hocking, J., P. Rayer, R. Saunders, M. Matricardi, A. Geer, and P. Brunel, 2011: RTTOV v10 users guide, NWC SAF Rep., EUMETSAT, Darmstadt, Germany, $92 \mathrm{pp}$.

Honda, T., and Coauthors, 2018a: Assimilating all-sky Himawari-8 satellite infrared radiances: A case of Typhoon Soudelor (2015). Mon. Wea. Rev., 146, 213-229, https://doi.org/10.1175/ MWR-D-16-0357.1.

—, S. Kotsuki, G.-Y. Lien, Y. Maejima, K. Okamoto, and Y. Miyoshi, 2018b: Assimilation of Himawari-8 all-sky radiances every 10 minutes: Impact on precipitation and flood risk prediction. J. Geophys. Res. Atmos., 123, 965-976, https:// doi.org/10.1002/2017JD027096.

Houtekamer, P. L., and F. Zhang, 2016: Review of the ensemble Kalman filter for atmospheric data assimilation. Mon. Wea. Rev., 144, 4489-4532, https://doi.org/10.1175/MWR-D-150440.1 .

Hunt, B. R., E. J. Kostelich, and I. Szunyogh, 2007: Efficient data assimilation for spatiotemporal chaos: A local ensemble transform Kalman filter. Physica D, 230, 112-126, https:// doi.org/10.1016/j.physd.2006.11.008.

Jones, T. A., and D. J. Stensrud, 2015: Assimilating cloud water path as a function of model cloud microphysics in an idealized simulation. Mon. Wea. Rev., 143, 2052-2081, https://doi.org/ 10.1175/MWR-D-14-00266.1.

_ J. A. Otkin, D. J. Stensrud, and K. Knopfmeier, 2013a: Assimilation of satellite infrared radiances and Doppler radar observations during a cool season observing system simulation experiment. Mon. Wea. Rev., 141, 3273-3299, https://doi.org/ 10.1175/MWR-D-12-00267.1.

— D. J. Stensrud, P. Minnis, and R. Palikonda, 2013b: Evaluation of a forward operator to assimilate cloud water path into WRF-DART. Mon. Wea. Rev., 141, 2272-2289, https:// doi.org/10.1175/MWR-D-12-00238.1.

— J. A. Otkin, D. J. Stensrud, and K. Knopfmeier, 2014: Forecast evaluation of an Observing System Simulation Experiment assimilating both radar and satellite data. Mon. Wea. Rev., 142, 107-124, https://doi.org/10.1175/MWR-D13-00151.1.

—, D. J. Stensrud, L. Wicker, P. Minnis, and R. Palikonda, 2015: Simultaneous radar and satellite data storm-scale assimilation using an ensemble Kalman filter approach for 24 May 2011. Mon. Wea. Rev., 143, 165-194, https://doi.org/ 10.1175/MWR-D-14-00180.1.

_ , K. Knopfmeier, D. Wheatley, G. Creager, P. Minnis, and R. Palikondo, 2016: The NSSL Multiscale Ensemble. Part II: Combined radar and satellite assimilation. Wea. Forecasting, 31, 297-327, https://doi.org/10.1175/WAF-D-15-0107.1.

_- , X. G. Wang, P. Skinner, A. Johnson, and Y. M. Wang, 2018: Assimilation of GOES-13 imager clear-sky water vapor $(6.5 \mathrm{mu} \mathrm{m})$ radiances into a Warn-on-Forecast system. Mon. Wea. Rev., 146, 1077-1107, https://doi.org/ 10.1175/MWR-D-17-0280.1.

Kazumori, M., A. J. Geer, and S. J. English, 2016: Effects of all-sky assimilation of GCOM-W/AMSR2 radiances in the ECMWF numerical weather prediction system. Quart. J. Roy. Meteor. Soc., 142, 721-737, https://doi.org/10.1002/qj.2669. 
Kerr, C. A., D. J. Stensrud, and X. Wang, 2015: Assimilation of cloud-top temperature and radar observations of an idealized splitting supercell using an observing system simulation experiment. Mon. Wea. Rev., 143, 1018-1034, https://doi.org/ 10.1175/MWR-D-14-00146.1.

Klaes, K. D., and Coauthors, 2007: An introduction to the EUMET- SAT Polar System. Bull. Amer. Meteor. Soc., 88, 1085-1096, https://doi.org/10.1175/BAMS-88-7-1085.

Kostka, P. M., M. Weissmann, R. Buras, B. Mayer, and O. Stiller, 2014: Observation operator for visible and near-infrared satellite reflectances. J. Atmos. Oceanic Technol., 31, 1216-1233, https://doi.org/10.1175/JTECH-D-13-00116.1.

Kurzrock, F., S. Cros, F. Chane-Ming, J. A. Otkin, L. Linguet, A. Hutt, G. Lajoie, and R. Potthast, 2018: The assimilation of geostationary meteorological satellite observations in regional NWP for cloudiness forecasting. Meteor. Z., 27, 277-298, https://doi.org/10.1127/metz/2018/0904.

Langland, R. H., and N. L. Baker, 2004: Estimation of observation impact using the NRL atmospheric variational data assimilation adjoint system. Tellus, 56A, 189-201, https://doi.org/ 10.3402/tellusa.v56i3.14413.

Lawrence, H., N. Bormann, A. J. Geer, Q. Lu, and S. J. English, 2018: Evaluation and assimilation of the Microwave Sounder MWHS-2 onboard FY-3C in the ECMWF numerical weather prediction system. IEEE Trans. Geosci. Remote Sens., 56 3333-3349, https://doi.org/10.1109/TGRS.2018.2798292.

Le Gleau, H., 2016: Algorithm theoretical basis document for the cloud products processors of the NWC/GEO. EUMETSAT NWC SAF, accessed 29 March 2017, http://www.nwcsaf.org.

Lien, G.-Y., T. Miyoshi, and E. Kalnay, 2016: Assimilation of TRMM Multisatellite Precipitation Analysis with a lowresolution NCEP global forecast system. Mon. Wea. Rev., 144, 643-661, https://doi.org/10.1175/MWR-D-15-0149.1.

Lin, Y. L., R. Farley, and H. Orville, 1983: Bulk parameterization of the snow field in a cloud model. J. Climate Appl. Meteor., 22, 1065-1092, https://doi.org/10.1175/1520-0450(1983)022<1065: BPOTSF $>2.0 . \mathrm{CO} ; 2$.

Lin, H., S. Weygandt, S. Benjamin, and M. Hu, 2017: Satellite radiance data assimilation with the hourly updated rapid refresh. Wea. Forecasting, 32, 1273-1287, https://doi.org/10.1175/ WAF-D-16-0215.1.

Lupu, C., and A. P. McNally, 2012: Assimilation of cloud-affected radiances from Meteosat-9 at ECMWF. EUMETSAT/ECMWF Fellowship Programme Research Rep. 25, ECMWF, Reading, United Kingdom, 35 pp., https://www.ecmwf.int/sites/default/ files/elibrary/2012/10859-assimilation-cloud-affected-radiancesmeteosat-9-ecmwf.pdf.

Mahfouf, J.-F., 2010: Assimilation of satellite-derived soil moisture from ASCAT in a limited-area NWP model. Quart. J. Roy. Meteor. Soc., 136, 784-798, https://doi.org/10.1002/QJ.602.

Majewski, D., and Coauthors, 2002: The operational Global Icosahedral-Hexagonal Gridpoint Model GME: Description and high-resolution tests. Mon. Wea. Rev., 130, 319-338, https://doi.org/10.1175/1520-0493(2002)130<0319:TOGIHG > 2.0.CO;2.

Mallick, S., D. Dutta, and K.-H. Min, 2017: Quality assessment and forecast sensitivity of global remote sensing observations. Adv. Atmos. Sci., 34, 371-382, https://doi.org/10.1007/ s00376-016-6109-8.

Matricardi, M., 2005: The inclusion of aerosols and clouds in RTIASI, the ECMWF fast radiative transfer model for the infrared atmospheric sounding interferometer. Tech. Memo. 474, ECMWF, Reading, United Kingdom, 55 pp.
McFarquhar, G. M., S. Iacobellis, and R. C. J. Somerville, 2003: SCM simulations of tropical ice clouds using observationally based parameterizations of microphysics. J. Climate, 16, 1643-1664, https://doi.org/10.1175/1520-0442(2003)016<1643: SSOTIC $>2.0 . \mathrm{CO} ; 2$.

McNally, A. P., 2002: A note on the occurrence of cloud in meteorologically sensitive areas and the implications for advanced infrared sounders. Quart. J. Roy. Meteor. Soc., 128, 2551-2556, https://doi.org/10.1256/qj.01.206.

, 2009: The direct assimilation of cloud-affected satellite infrared radiances in the ECMWF 4D-Var. Quart. J. Roy. Meteor. Soc., 135, 1214-1229, https://doi.org/10.1002/qj.426.

Minamide, M., and F. Zhang, 2017: Adaptive observation error inflation for assimilating all-sky satellite radiance. Mon. Wea. Rev., 145, 1063-1081, https://doi.org/10.1175/MWR-D-160257.1.

— and - 2018: Assimilation of all-sky infrared radiances from Himawari- 8 and impacts of moisture and hydrometer initialization on convection-permitting tropical cyclone prediction. Mon. Wea. Rev., 146, 3241-3258, https://doi.org/ 10.1175/MWR-D-17-0367.1.

Miyoshi, T., Y. Sato, and T. Kadowaki, 2010: Ensemble Kalman filter and 4D-Var intercomparison with the Japanese operational global analysis and prediction system. Mon. Wea. Rev., 138, 2846-2866, https://doi.org/10.1175/2010MWR3209.1.

Nakamura, G., and R. Potthast, 2015: Inverse Modeling: An Introduction to the Theory and Methods of Inverse Problems and Data Assimilation. IOP Publishing, https://doi.org/10.1088/ 978-0-7503-1218-9.

Okamoto, K., 2013: Assimilation of overcast cloudy infrared radiances of the geostationary MTSAT-1R imager. Quart. J. Roy. Meteor. Soc., 139, 715-730, https://doi.org/10.1002/ qj.1994.

_ 2017: Evaluation of IR radiance simulation for all-sky assimilation of Himawari-8/AHI in a mesoscale NWP system. Quart. J. Roy. Meteor. Soc., 143, 1517-1527, https://doi.org/ 10.1002/qj.3022.

, A. P. McNally, and W. Bell, 2014: Progress towards the assimilation of all-sky infrared radiances: An evaluation of cloud effects. Quart. J. Roy. Meteor. Soc., 140, 1603-1614, https:// doi.org/10.1002/qj.2242.

, Y. Sawada, and M. Kunii, 2019: Comparison of assimilating all-sky and clear-sky infrared radiances from Himawari-8 in a mesoscale system. Quart. J. Roy. Meteor. Soc., 145, 745-766, https://doi.org/10.1002/qj.3463.

Otkin, J. A., 2010: Clear and cloudy sky infrared brightness temperature assimilation using an ensemble Kalman filter. J. Geophys. Res., 115, D19207, https://doi.org/10.1029/ 2009JD013759.

2012a: Assessing the impact of the covariance localization radius when assimilating infrared brightness temperature observations using an ensemble Kalman filter. Mon. Wea. Rev., 140, 543-561, https://doi.org/10.1175/MWR-D11-00084.1.

, 2012b: Assimilation of water vapor sensitive infrared brightness temperature observations during a high impact weather event. J. Geophys. Res., 117, D19203, https://doi.org/ 10.1029/2012JD017568.

— simulated and MODIS-derived cloud data. Mon. Wea. Rev., 136, 1957-1970, https://doi.org/10.1175/2007MWR2293.1.

, R. Potthast, and A. Lawless, 2018: Nonlinear bias correction for satellite data assimilation using Taylor series 
polynomials. Mon. Wea. Rev., 146, 263-285, https://doi.org/ 10.1175/MWR-D-17-0171.1.

Pan, S. J., J. D. Gao, D. J. Stensrud, X. G. Wang, and T. A. Jones, 2018: Assimilation of radar radial velocity and reflectivity, satellite cloud water path, and total precipitable water for convective-scale NWP in OSSEs. J. Atmos. Oceanic Technol., 35, 67-89, https://doi.org/10.1175/JTECH-D-17-0081.1.

Pangaud, T., N. Fourrie, V. Guidard, M. Dahoui, and F. Rabier, 2009: Assimilation of AIRS radiances affected by mid- to lowlevel clouds. Mon. Wea. Rev., 137, 4276-4292, https://doi.org/ 10.1175/2009MWR3020.1.

Parrish, D. F., and J. C. Derber, 1992: The National Meteorological Center's spectral statistical interpolation analysis system. Mon. Wea. Rev., 120, 1747-1763, https://doi.org/ 10.1175/1520-0493(1992)120<1747:TNMCSS > 2.0.CO;2.

Pavelin, E. G., S. J. English, and J. R. Eyre, 2008: The assimilation of cloud-affected infrared satellite radiances for numerical weather prediction. Quart. J. Roy. Meteor. Soc., 134, 737-749, https://doi.org/10.1002/qj.243.

Perianez, A., H. Reich, and R. Potthast, 2014: Optimal localization for ensemble Kalman filter systems. J. Meteor. Soc. Japan, 92, 585-597, https://doi.org/10.2151/jmsj.2014-605.

Peubey, C., and A. P. McNally, 2009: Characterization of the impact of geostationary clear-sky radiances on wind analyses in a 4D-Var context. Quart. J. Roy. Meteor. Soc., 135, 1863-1876, https://doi.org/10.1002/qj.500.

Raisanen, P., 1998: Effective longwave cloud fraction and maximum-random overlap of clouds: A problem and a solution. Mon. Wea. Rev., 126, 3336-3340, https://doi.org/ 10.1175/1520-0493(1998)126<3336:ELCFAM>2.0.CO;2.

Raschendorfer, M., 2001: The new turbulence parameterisation of LM. COSMO Newsl., 1, 89-97.

Ritter, B., and J. F. Geleyn, 1992: A comprehensive radiation scheme for numerical weather prediction models with potential applications in climate simulations. Mon. Wea. Rev., 120, 303-325, https://doi.org/10.1175/1520-0493(1992)120<0303: ACRSFN $>2.0 . \mathrm{CO} ; 2$.

Saunders, R., M. Matricardi, and P. Brunel, 1999: An improved fast radiative transfer model for assimilation of satellite radiance observations. Quart. J. Roy. Meteor. Soc., 125, 1407-1425, https://doi.org/10.1002/qj.1999.49712555615.

Schmetz, J., P. Pili, S. Tjemkes, D. Just, J. Lerkmann, S. Rota, and A. Ratier, 2002: An introduction to Meteosat Second Generation (MSG). Bull. Amer. Meteor. Soc., 83, 977-992, https:// doi.org/10.1175/1520-0477(2002)083<0977:AITMSG>2.3.CO;2.

Schmit, T. J., P. Griffith, M. M. Gunshor, J. M. Daniels, S. J. Goodman, and W. J. Lebair, 2017: A closer look at the ABI on the GOES-R series. Bull. Amer. Meteor. Soc., 98, 681-698, https://doi.org/10.1175/BAMS-D-15-00230.1.

Schomburg, A., C. Schraff, and R. Potthast, 2015: A concept for the assimilation of satellite cloud information in an Ensemble Kalman Filter: Single-observation experiments. Quart. J. Roy. Meteor. Soc., 141, 893-908, https://doi.org/10.1002/ qj. 2407.

Schraff, C., H. Reich, A. Rhodin, A. Schomburg, K. Stephan, A. Perianez, and R. Potthast, 2016: Kilometer-scale ensemble data assimilation for the COSMO model (KENDA). Quart. J. Roy. Meteor. Soc., 142, 1453-1472, https://doi.org/ 10.1002/qj.2748.

Seifert, A., and K. Beheng, 2001: A double-moment parameterization for simulating autoconversion, accretion and selfcollection. Atmos. Res., 59-60, 265-281, https://doi.org/ 10.1016/S0169-8095(01)00126-0.
Stengel, M., P. Unden, M. Lindskog, P. Dahlgren, N. Gustafsson, and R. Bennartz, 2009: Assimilation of SEVIRI infrared radiances with HIRLAM 4D-Var. Quart. J. Roy. Meteor. Soc., 135, 2100-2109, https://doi.org/10.1002/qj.501.

- M. Lindskog, P. Unden, and N. Gustafsson, 2013: The impact of cloud-affected IR radiances on forecast accuracy of a limited-area NWP model. Quart. J. Roy. Meteor. Soc., 139, 2081-2096, https://doi.org/10.1002/qj.2102.

Strow, L. L., and Coauthors, 2013: Spectral calibration and validation of the Cross-track Infrared Sounder on the Suomi NPP satellite. J. Geophys. Res. Atmos., 118, 12 486-12 496, https:// doi.org/10.1002/2013JD020480.

Szunyogh, I., E. J. Kostelich, G. Gyarmati, E. Kalnay, B. R. Hunt, E. Ott, E. Satterfield, and J. A. Yorke, 2008: A local ensemble transform Kalman filter data assimilation system for the NCEP global model. Tellus, 60A, 113-130, https://doi.org/ 10.1111/j.1600-0870.2007.00274.x.

Tiedtke, M., 1989: A comprehensive mass flux scheme for cumulus parameterisation in large-scale models. Mon. Wea. Rev., 117, 1779-1799, https://doi.org/10.1175/1520-0493(1989)117<1779: ACMFSF $>2.0 . \mathrm{CO} ; 2$.

Vukicevic, T., T. Greenwald, M. Zupanski, D. Zupanski, T. Vonder Haar, and A. S. Jones, 2004: Mesoscale cloud state estimation from visible and infrared satellite radiances. Mon. Wea. Rev., 132, 3066-3077, https://doi.org/10.1175/ MWR2837.1.

— M. Sengupta, A. S. Jones, and T. Vonder Haar, 2006: Cloudresolving satellite data assimilation: Information content of IR window observations and uncertainties in estimation. J. Atmos. Sci., 63, 901-919, https://doi.org/10.1175/JAS3639.1.

Wang, P., J. Li, B. Lu, T. J. Schmit, J. Lu, Y.-K. Lee, J. Li, and Z. Liu, 2018: Impact of moisture information from Advanced Himawari Imager measurements on heavy precipitation forecasts in a regional NWP model. J. Geophys. Res. Atmos., 123, 6022-6038, https://doi.org/10.1029/2017JD028012.

Wu, T.-C., M. Zupanski, L. D. Grasso, C. D. Kummerow, and S.-A. Boukabara, 2019: All-sky radiance assimilation of ATMS in HWRF: A demonstration study. Mon. Wea. Rev., 147, 85-106, https://doi.org/10.1175/MWR-D-17-0337.1.

Yang, C., Z. Liu, J. Bresch, S. R. Rizvi, X. Y. Huang, and J. Min, 2016: AMSR2 all-sky radiance assimilation and its impact on the analysis and forecast of Hurricane Sandy with a limitedarea data assimilation system. Tellus, 68A, 30917, https:// doi.org/10.3402/tellusa.v68.30917.

Yang, P., L. Bi, B. A. Baum, K.-N. Liou, G. Kattawar, M. Mishchenko, and B. Cole, 2013: Spectrally consistent scattering, absorption, and polarization properties of atmospheric ice crystals at wavelengths from $0.2 \mu \mathrm{m}$ to $100 \mu \mathrm{m}$. J. Atmos. Sci., 70, 330-347, https://doi.org/10.1175/ JAS-D-12-039.1.

Yi, B., P. Yang, Q. Liu, P. van Delst, S.-A. Boukabara, and F. Weng, 2016: Improvements on the ice cloud modeling capabilities of the Community Radiative Transfer Model. J. Geophys. Res. Atmos., 121, 13 577-13 590, https://doi.org/ 10.1002/2016JD025207.

Zangl, G., D. Reinert, P. Ripodas, and M. Baldauf, 2015: The ICON (ICOsahedral Non-hydrostatic) modelling framework of DWD and MPI-M: Description of the non-hydrostatic dynamical core. Quart. J. Roy. Meteor. Soc., 141, 563-579, https:// doi.org/10.1002/qj.2378.

Zhang, F., C. Snyder, and J. Sun, 2004: Impacts of initial estimate and observation availability on convective-scale data assimilation with an ensemble Kalman filter. Mon. Wea. Rev., 132, 
1238-1253, https://doi.org/10.1175/1520-0493(2004)132<1238: IOIEAO $>2.0 . \mathrm{CO} ; 2$

- M. Minamide, and E. Clothiaux, 2016: Potential impacts of assimilating all-sky infrared satellite radiances from GOES-R on convection-permitting analysis and prediction of tropical cyclones. Geophys. Res. Lett., 43, 2954-2963, https://doi.org/ 10.1002/2016GL068468.

Zhang, M., F. Zhang, X.-Y. Huang, and X. Zhang, 2011: Intercomparison of an ensemble Kalman filter with three- and four-dimensional variational data assimilation methods in a limited-area model over the month of June 2003. Mon. Wea Rev., 139, 566-572, https://doi.org/10.1175/2010MWR3610.1.

Zhang, S., and L. Guan, 2017: Preliminary study on direct assimilation of cloud-affected satellite brightness temperatures. Adv. Atmos. Sci., 34, 199-208, https://doi.org/10.1007/s00376-016-6043-9.

Zhang, Y. J., F. Q. Zhang, and D. J. Stensrud, 2018: Assimilating all-sky infrared radiances from GOES-16 ABI using an ensemble Kalman filter for convection-allowing severe thunderstorms prediction. Mon. Wea. Rev., 146, 3363-3381, https:// doi.org/10.1175/MWR-D-18-0062.1.

Zhu, Y., J. Derber, A. Collard, D. Dee, R. Treadon, G. Gayno, and J. A. Jung, 2014: Enhanced radiance bias correction in the National Centers for Environmental Prediction's Gridpoint Statistical Interpolation data assimilation system. Quart. J. Roy. Meteor. Soc., 140, 1479-1492, https://doi.org/ 10.1002/qj.2233.

- and Coauthors, 2016: All-sky microwave radiance assimilation in NCEP's GSI analysis system. Mon. Wea. Rev., 144, 4709-4735, https://doi.org/10.1175/MWR-D-15-0445.1.

Zupanski, D., M. Zupanski, L. D. Grasso, R. Brummer, I. Jankov, D. Lindsey, M. Sengupta, and M. Demaria, 2011: Assimilating synthetic GOES-R radiances in cloudy conditions using an ensemble-based method. Int. J. Remote Sens., 32, 9637-9659, https://doi.org/10.1080/01431161.2011.572094. 